Estudios sobre armas antiguas, arte militar $\mathrm{y}$ vida cultural en oriente y occidente

XLI (2021), pp. 153-176

ISSN: 0436-029X; eISSN: 1988-4168

https://doi.org/10.3989/gladius.2021.09

\title{
«BERNARDINO DE TEXEDA ME FECIT»: ARTILLERÍA VIRREINAL DEL PERÚ A FINALES DEL SIGLO XVI
}

\author{
“BERNARDINO DE TEXEDA ME FECIT": PERUVIAN COLONIAL ARTILLERY IN THE \\ LATE $16^{\mathrm{TH}}$ CENTURY
}

POR

\author{
Juan Jesús Oliver Laso* y Abraham Ramírez Pernía**
}

\section{RESUMEN - ABSTRACT}

Este trabajo de investigación estudia y analiza las dos piezas de artillería recuperadas en el yacimiento de la fragata Nuestra Señora de las Mercedes. Asimismo, se revisa el estado teórico de la artillería española de los siglos XVI y XVII y se realiza una aproximación a la producción artillera de la ciudad de Lima para estas centurias. Finalmente se revisa la trayectoria profesional del maestro fundidor Bernardino de Tejeda.

This work studies and analyzes two pieces of artillery recovered in the archaeological site of the Nuestra Senora de las Mercedes frigate. Moreover, the theoretical treatises of Spanish artillery in the $16^{\text {th }}$ and $17^{\text {th }}$ centuries are discussed. The artillery production of the city of Lima on these centuries is also examined. Finally, the professional career of the foundry master Bernardino de Tejeda is highlighted.

\section{Palabras Clave - Keywords}

Culebrinas; Lima; artillería; fundidores; Nuestra Señora de las Mercedes.

Culverins; Lima; artillery; smelters; Nuestra Señora de las Mercedes.

\section{CÓMO CITAR ESTE ARTículo / CitATION}

Oliver Laso, J. J. y Ramírez Pernía, A. (2021): «“Bernardino de Texeda me fecit”: Artillería virreinal del Perú a finales del siglo XVI». Gladius, 41: 153-176. https://doi.org/10.3989/gladius.2021.09

RECIBIDO / RECEIVED: 10-04-2019

ACEPTADO / ACCEPTED: 10-05-2020

* Asociación Española de Historia Naval y Marítima, jjoliverlaso@gmail.com / ORCID iD: https://orcid.org/0000-0003$4426-4529$

** Museo Nacional de Arqueología Subacuática (ARQVA), Área de Documentación, abraham.ramirez@cultura.gob.es / ORCID iD: https://orcid.org/0000-0002-3570-7933

Copyright: (C) 2021 CSIC. Este es un artículo de acceso abierto distribuido bajo los términos de la licencia de uso y distribución Creative Commons Reconocimiento 4.0 Internacional (CC BY 4.0). 


\section{INTRODUCCIÓN}

Al amanecer del 5 de octubre de 1804, cuatro fragatas españolas, comandadas por José de Bustamante y Guerra, que respondían a los nombres de Clara, Medea, Fama y Mercedes fueron interceptadas por una escuadra de la armada británica (Medusa, Lively, Amphion e Indefatigable). Este encuentro se produjo cerca del cabo de Santa María (Algarve portugués), cuando las naves españolas se disponían a llegar a Cádiz. Ante la negativa española de entregar el cargamento que transportaban se inició el combate (García y Mar$\cos , 2014)$. A las nueve de la mañana, señala Diego de Alvear, «saltó la Mercedes por los aires con estruendo horrible» (Alvear, 1891: 108). Una bala había impactado con su santabárbara haciéndola estallar (Fernández Duro, 1902). El combate terminó con la Fama, Clara y Medea apresadas por las fragatas inglesas, al tiempo que los restos de la Mercedes descansaban sobre el lecho marino, a 1138 metros de profundidad.

Dos siglos después del ominoso naufragio, la empresa Odyssey Marine Exploration sustrajo parte del cargamento de la Mercedes. En 2009 el Gobierno español reclamó legalmente la recuperación de los restos arqueológicos expoliados ante el tribunal de Tampa, en EEUU (Leste, 2013) y el 25 de febrero de 2012 regresaron a España los materiales que fueron sustraídos ilegalmente del pecio.

Para comprobar el estado en el que había quedado el yacimiento de la Mercedes, el Ministerio de Educación Cultura y Deporte encargó

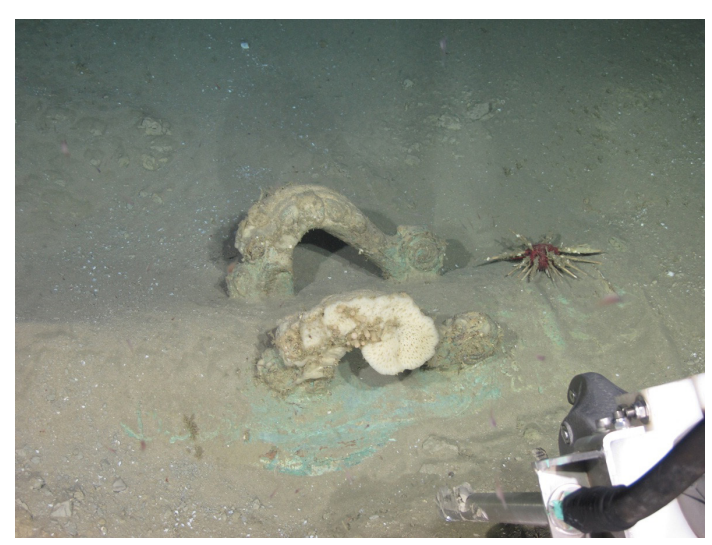

Figura 1. Detalle de los delfines de una de las culebrinas localizadas en el yacimiento de la fragata Mercedes. (C) Archivo Museo Nacional de Arqueología Subacuática / Instituto Español de Oceanografía. al Museo Nacional de Arqueología Subacuática (ARQVA) en colaboración con el Instituto Español de Oceanografía (IEO), la Armada Española y el Consejo Superior de Investigaciones Científicas (CSIC), la realización de tres campañas arqueológicas sobre este (Negueruela et alii, 2015), realizándose consecutivamente durante los años 2015, 2016 y 2017. Los resultados obtenidos demostraron científicamente los deterioros ocasionados por los cazatesoros. Además, se decidió la recuperación de algunos objetos con valor científico para su investigación, entre los que se encontraban las dos piezas de artillería que sometemos a estudio en estas líneas.

\section{PROBLEMÁTICA CLASIFICACIÓN DE LA ARTILLERÍA ESPAÑOLA EN LOS SIGLOS XVI Y XVII}

\subsection{LA HETEROGENEIDAD COMO NORMA}

Estas dos centurias se caracterizaron por la existencia de una gran variedad de piezas y la denotada ausencia de una norma estricta que regulase su producción. Dicha heterogeneidad se tradujo en multitud de medidas, calibres y nombres por los que eran reconocidas. Jorge Vigón, afirmó que: «Los constructores y los usuarios, y más tarde los cronistas, a cubierto de toda precaución científica, crearon para la denominación de las bocas de fuego la más copiosa y arbitraria onomástica» (Vigón, 1947: 33). Sus palabras se complementan muy bien con las emitidas por Vicente de los Ríos: «Inundaronse los Ejercitos, y Plazas de Dragones, Aspides, Basiliscos, Serpentines, Serenas, Pelicanos, Sacres, Falcones, Falconetes, Girifaltes, Ribadoquines, Esmeriles, Pasadores, Culebrinas y sus derivados [...] Molesto sería referirlos todos» (Ríos, 1767: 61).

Este infausto escenario para la artillería elaborada en los territorios de la monarquía hispánica se generó como consecuencia de los conocimientos teóricos y prácticos que cada maestro fundidor tenía para producir sus piezas, ya que estos se transmitían de generación en generación, sin dejar apenas constancia escrita de los mismos, evitando que fueran adquiridos por otros fundidores. El resultado de esta situación era el riesgo al que se exponían los artilleros que manejaban en un mismo lugar diferentes piezas de distinto calibre. El error de introducir una bala en el cañón equivocado podía provocar que al dispararla esta se atorase 
en el ánima y la pieza estallase (si era de hierro) o se resquebrajara como ocurría con las de bronce.

En este sentido, Luis Collado, en su obra Plática Manual de Artillería, expuso el problema y señaló que «las balas de las pieças de un presidio no pueden servir á aquellas del otro» y que «a cada pieça de Artilleria se requiere su particular cuchara, de donde resulta que por tanta multitud de cucharas se causa gran confusion en las empresas» (Collado, 1592: 9). Además, puso como ejemplo concreto el castillo de Milán:

Donde ay grandisimo numero de pieças de Artilleria a, Conviene à saber Smeriles, Falconetes, Medios Sacres, Aspides, Medias Culebrinas, $\mathrm{Cu}-$ lebrinas, Quartos, y medios Cañones, Cañones y dos Basaliscos, cada una pieça de las dichas han menester sus particulares Cucharas, y otros tantos Estivadores, y otras tantas Lanadas, Y las pieças que se podían cargar con solo 11 Cucharas, por no ser mas de 11 differencias de pieças, han menester mas de 200 y otros tantos Estiuadores, y otras tantas Lanadas (Collado, 1592: 9).

\subsection{LA INSUFICIENTE SOLUCIÓN AL PROBLEMA}

La ausencia de una norma en la producción artillera llevó a diversos autores a enunciar, en función de su experiencia y conocimientos, sus propios criterios para gestionar esa multitud de piezas que inundaban los buques, fortificaciones y campos de batalla de la época. Uno de los primeros que dejó constancia del problema y planteó una solución fue Diego de Alaba. En 1590 se publicó su obra titulada El perfecto capitán instruido en la disciplina militar, y nueva ciencia de la artilleria donde abogaba por:

Reduzír á tres generos de pieças todas las que comúnmente se usan, teniendo respeto á las ofensas que al enemigo se le puede hazer, que en tierra seran haciendo de lexos estrago en su gente. Para lo qual servira la primer suerte de pieças, ó derribando de cerca murallas, torres, y otras máquinas de guerra, que es lo que se haze con las pieças del segundo genero, ó echando á fondo navios y galeras, para cuyo efeto se traçaron las pieças del tercer genero (Alaba, 1590: 159).

De Alaba establece la primera división de la artillería en tres grupos, en función de la distancia que con el disparo se quiera alcanzar y el daño que se busque producir. También especifica que para poder agrupar en un mismo género diferen- tes piezas, estas deben corresponderse entre sí en función de su longitud y anchura, además de por su calibre o peso de bala (expresado en libras). En este sentido agrupa en el primer género, denominado culebrinas, aquellas cuya longitud no exceda los 32 diámetros del diámetro de su boca y su calibre no superase las 45 libras. Comprende dentro de este: mosquetes, esmeriles, falconetes, pasavolantes, cebratanas, sacres, moyanas, medias culebrinas y culebrinas.

Tabla 1. Clasificación de las piezas de artillería según Diego de Alaba (1590). Elaboración propia a partir de la obra El perfecto capitán instruido en la disciplina militar, y nueva ciencia de la artillería.

\begin{tabular}{|c|c|c|}
\hline \multicolumn{3}{|c|}{ Primer género: Culebrinas } \\
\hline Nombre & $\begin{array}{c}\text { Calibre } \\
\text { (bala de hierro) }\end{array}$ & Diámetros \\
\hline Mosquete & 2 onzas (de plomo) & $\leq 32$ \\
\hline Esmeril & $\begin{array}{c}\text { De } 6 \text { hasta } 12 \text { onzas } \\
\text { (de plomo) }\end{array}$ & $\leq 32$ \\
\hline Falconete & De 3 a 4 libras & $\leq 32$ \\
\hline Pasavolante & De 5 a 6 libras & $\leq 32$ \\
\hline Cebratana & De 5 a 6 libras & $\leq 32$ \\
\hline Sacre & De 8 a 10 libras & $\leq 32$ \\
\hline Moyana & De 8 a 10 libras & $\leq 32$ \\
\hline $\begin{array}{c}\text { Media cule- } \\
\text { brina }\end{array}$ & De 12 a 18 libras & $\leq 32$ \\
\hline Culebrina & De 20 a 45 libras & $\leq 32$ \\
\hline \multicolumn{3}{|c|}{ Segundo género: Cañones } \\
\hline Nombre & $\begin{array}{c}\text { Calibre } \\
\text { (bala de hierro) }\end{array}$ & Diámetros \\
\hline $\begin{array}{l}\text { Cañón de } \\
\text { batir }\end{array}$ & De 35 a 60 libras & 18 \\
\hline Medio Cañón & De 35 a 60 libras & De 22 a 24 \\
\hline $\begin{array}{l}\text { Cuarto de } \\
\text { cañón }\end{array}$ & De 35 a 60 libras & De 22 a 28 \\
\hline \multicolumn{3}{|c|}{ Tercer género: Pedreros } \\
\hline Nombre & $\begin{array}{c}\text { Calibre } \\
\text { (bala de piedra) }\end{array}$ & Diámetros \\
\hline $\begin{array}{c}\text { Cañón pe- } \\
\text { drero }\end{array}$ & - & 8 \\
\hline
\end{tabular}

En el segundo género, titulado cañones, agrupa las que tienen una longitud inferior a las culebrinas pero su calibre es superior. Su finalidad es abatir edificaciones, por lo que la potencia debe 
ser superior al alcance. En este grupo De Alaba solo reúne los cañones de batir, los medios cañones y los cuartos de cañón. Finalmente agrupa en un tercer género intitulado pedreros aquellas piezas que por sus prestaciones en el combate a corta distancia y su efectividad contra personal enemigo: «La mayor parte sirven en la mar; y a necesidad en tierra para impedir la entrada de alguna ciudad o lugar. Tiran pelotas de piedra de mucho peso, gavias de piedra, cadenas y otras cosas semejantes» (Alaba, 1590: 162).

Se trata de bocas de fuego de gran calibre pero muy ligeras y versátiles. Su finalidad es actuar en combates a corta distancia contra un grupo de enemigos o personal equipado con petos y rodelas, por lo que se consideran armas «antidotación» (Fondevila y Sánchez, 2012: 192).

Trascurridos dos años de la publicación del Perfecto Capitán, Luis Collado, ingeniero y militar al servicio de Felipe II en el ejército de Lombardía y Piamonte (Diana, 1851: 36), publica su obra titulada Plática Manual de Artillería. En esta mantiene la propuesta de Diego de Alaba al aludir a los tres géneros y afirma que:

La distincion de los generos dichos de Artilleria, es á los Artilleros de tanta claidad y inportancia, que sin duda alguna, el que ignora la presente platica, jamas acerca de este arte artara á hazer cosa buena, $\mathrm{Ni}$ menos se puede negar en la causa de haverse fundido tanta diversidad de pieças de Artilleria, y con tanta increíble gasto de los Principes, que la mandan fundir, Y la gran confusión de Balas, y $\mathrm{Cu}-$ charas, El rebentarse en las tareas cada dia tantas pieças, haver procedido de no haverse tenido verdadera noticia de la division, y distinción susodicha (Collado, 1592: 27).

Collado mantiene para el primer género las piezas propuestas por Diego de Alaba a las que añade los ribadoquines y los medios sacres. Respecto al segundo, este lo formarían: los «cañones de batería o de batir» (Collado, 1592: 27) (indicando que dentro de estos hay: encamarados, encampanados, sencillos, dobles y reforzados), el cuarto cañón, el medio cañón, el cañón sencillo o común, el doble cañón y el basilisco. Todos ellos con calibres muy superiores a los del primer género pero con más metal y de menor longitud.

Por último, en el tercer género, incluye además de los pedreros, los trabucos y los morteros. A diferencia de Alaba inserta aquí también «las bombardas de hierro que forjaron los antiguos» (Collado, 1592: 34), posiblemente porque estas se componían de dos partes (caña y másculo) al igual que la mayoría de los pedreros y algunas de ellas eran pequeñas y maniobrables gracias a su poco peso y el uso de una horquilla para guiar el disparo. Debemos destacar que para este grupo Collado no facilita datos precisos sobre diámetros y calibres.

Tabla 2. Clasificación de las piezas de artillería según Luis Collado (1592). Elaboración propia a partir de los datos extraídos en su obra Plática manual de artillería.

\begin{tabular}{|c|c|c|}
\hline \multicolumn{3}{|c|}{ Primer género: Culebrinas } \\
\hline Nombre & $\begin{array}{c}\text { Calibre } \\
\text { (bala de hierro) }\end{array}$ & Diámetros \\
\hline Mosquete & 2 onzas (de plomo) & $\leq 32$ \\
\hline Ribadoquín & - & $\leq 32$ \\
\hline Esmeril & $\begin{array}{c}\text { De } 6 \text { a } 12 \text { onzas (de } \\
\text { plomo) }\end{array}$ & $\leq 32$ \\
\hline Falconete & De 3 a 4 libras & $\leq 32$ \\
\hline Medio sacre & De 5 a 7 libras & $\leq 32$ \\
\hline $\begin{array}{c}\text { Pasavolante o } \\
\text { cebratana }\end{array}$ & 6 libras aprox. & $\leq 32$ \\
\hline Sacre & De 8 a 10 libras & $\leq 32$ \\
\hline Moyana & De 8 a 10 libras & $\leq 32$ \\
\hline $\begin{array}{l}\text { Media cule- } \\
\text { brina }\end{array}$ & De 12 a 18 libras & $\leq 32$ \\
\hline Culebrina & De 20 a 50 libras & $\leq 32$ \\
\hline \multicolumn{3}{|c|}{ Segundo Género: Cañones } \\
\hline Nombre & $\begin{array}{c}\text { Calibre } \\
\text { (bala de hierro) }\end{array}$ & Diámetros \\
\hline $\begin{array}{l}\text { Cañón sencillo } \\
\text { o común }\end{array}$ & De 45 a 60 libras & 18 \\
\hline $\begin{array}{l}\text { Cuarto de } \\
\text { cañón }\end{array}$ & De 12 a 15 libras & De 28 a 26 \\
\hline Medio cañón & De 10 a 12 libras & De 22 a 24 \\
\hline $\begin{array}{l}\text { Cañón refor- } \\
\text { zado }\end{array}$ & 60 libras máximo & - \\
\hline Cañón doble & 80 libras o más & - \\
\hline Basiliscos & De 150 a 200 libras & 12 \\
\hline \multicolumn{3}{|c|}{ Tercer Género: Pedreros } \\
\hline Nombre & $\begin{array}{c}\text { Calibre } \\
\text { (bala de piedra) }\end{array}$ & Diámetros \\
\hline Pedrero & - & - \\
\hline $\begin{array}{l}\text { Trabuco (mor- } \\
\text { tero) }\end{array}$ & - & \\
\hline
\end{tabular}


En 1611 Cristoval Lechuga, teniente general de la artillería española en Flandes (Ríos, 1767: 54), publicó su Discurso del Capitán Cristoval Lechuga, en que trata de la Artilleria, y de todo lo necessario á ella. En esta aboga por mantener la clasificación de las bocas de fuego en tres géneros y al mismo tiempo reducir las piezas que los integran. Según su criterio, el género culebrinas estaría compuesto por tres piezas al igual que el de cañones. Cuando habla de estas piezas establece las medidas que cada una de ellas debe tener, según sus conocimientos y experiencia, pero no así sus calibres pues afirma que estos están supeditados «a la voluntad del señor que lo quiera hacer» (Lechuga, 1611: 1). Por último, del tercer género, al igual que ocurría con Collado, apenas le muestra importancia pues solo habla de dos piezas y no establece medidas firmes.

Tabla 3. Clasificación de las piezas de artillería según Cristoval Lechuga (1611). Elaboración propia a partir de los datos extraídos de su obra Discurso del Capitán Cristoval Lechuga, en que trata de la Artilleria, y de todo lo necessario á ella.

\begin{tabular}{|c|c|c|}
\hline \multicolumn{3}{|c|}{ Primer género: Culebrinas } \\
\hline Nombre & $\begin{array}{c}\text { Calibre } \\
\text { (bala de hierro) }\end{array}$ & Diámetros \\
\hline $\begin{array}{l}\text { Culebrina } \\
\text { entera }\end{array}$ & $\begin{array}{c}\text { No superior a } 20 \\
\text { libras }\end{array}$ & 36 \\
\hline $\begin{array}{l}\text { Media cule- } \\
\text { brina }\end{array}$ & Aprox. 10 libras & 38 \\
\hline $\begin{array}{l}\text { Cuarto de } \\
\text { culebrina }\end{array}$ & Aprox. 5 libras & 41 \\
\hline \multicolumn{3}{|c|}{ Segundo género: Cañones } \\
\hline Nombre & $\begin{array}{c}\text { Calibre } \\
\text { (bala de hierro) }\end{array}$ & Diámetros \\
\hline Cañón de batir & De 40 a 46 & 5 \\
\hline Medio cañón & - & 21 \\
\hline $\begin{array}{l}\text { Cuarto de } \\
\text { cañón }\end{array}$ & - & 27 \\
\hline \multicolumn{3}{|c|}{ Tercer género: Pedreros } \\
\hline Nombre & $\begin{array}{c}\text { Calibre } \\
\text { (bala de piedra) }\end{array}$ & Diámetros \\
\hline Mortero & - & - \\
\hline Petardo & - & - \\
\hline
\end{tabular}

Años más tarde, en 1613, Diego Ufano publicó su Tratado de Artillería y uso della Platica- do por el capitan Diego Ufano en las guerras de Flandes. Si consideramos que Cristoval Lechuga tiende a disminuir las piezas que forman cada género para facilitar la labor de quienes las producen y usan, Ufano no solo aumenta desmesuradamente el número de estas, sino que también les atribuye una serie de nombres que se encontraban ya extintos en las anteriores clasificaciones citadas. En este sentido, Arántegui expone que Ufano «ha fantaseado algo en lo relativo a nombres y clasificación de piezas» (Arantegui, 1891: 339). Por su parte, Fondevila Silva, argumenta que este actuó «creando una copiosa selva de datos y tablas que pudiera servir para acrecentar su prestigio, pero que crearon una enorme confusión» (Fondevila y Sánchez, 2012: 188). Lo cierto es que Ufano, respecto a los autores anteriormente nombrados, es el primero que, con mayor o menor acierto, se aventura a establecer el peso de las piezas que componen cada género y también es el primero que se olvida del tercer género y sus piezas.

Tabla 4. Clasificación de las piezas de artillería según Diego Ufano (1613). Elaboración propia a partir de los datos extraídos de su obra Tratado de Artilleria y uso della Platicado por el capitan Diego Ufano en las guerras de Flandes.

\begin{tabular}{|c|c|c|c|}
\hline \multicolumn{4}{|c|}{ Primer género: Culebrinas } \\
\hline Nombre & $\begin{array}{c}\text { Calibre } \\
\text { (bala de } \\
\text { hierro) }\end{array}$ & $\begin{array}{c}\text { Diáme- } \\
\text { tros }\end{array}$ & $\begin{array}{c}\text { Peso } \\
\text { (Quintales) }\end{array}$ \\
\hline $\begin{array}{c}\text { Dragón o } \\
\text { doble cule- } \\
\text { brina }\end{array}$ & 40 libras & 31 & 120 \\
\hline $\begin{array}{c}\text { Culebrina } \\
\text { común }\end{array}$ & 20 libras & 32 & 70 \\
\hline $\begin{array}{c}\text { Media cule- } \\
\text { brina }\end{array}$ & 10 libras & 33 & 41,5 \\
\hline $\begin{array}{c}\text { Sacre } \\
\text { ordinario o } \\
\text { cuarto } \\
\text { de culebrina }\end{array}$ & 5 libras & 34 & 25 \\
\hline $\begin{array}{c}\text { Falconete } \\
\text { (octava parte } \\
\text { de la } \\
\text { culebrina } \\
\text { ordinaria) }\end{array}$ & 2,5 libras & 35 & 13 \\
\hline $\begin{array}{c}\text { Rivadoquin } \\
\text { onzas }\end{array}$ & 1 libra y 4 & 36 & 7,5 \\
\hline
\end{tabular}




\begin{tabular}{|c|c|c|c|}
\hline \multicolumn{4}{|c|}{ Primer género: Culebrinas } \\
\hline Nombre & $\begin{array}{c}\text { Calibre } \\
\text { (bala de } \\
\text { hierro) }\end{array}$ & $\begin{array}{l}\text { Diáme- } \\
\text { tros }\end{array}$ & $\begin{array}{c}\text { Peso } \\
\text { (Quintales) }\end{array}$ \\
\hline Esmeril & $\begin{array}{c}15 \text { onzas } \\
\text { (de plomo) } \\
\text { o } 10 \text { onzas }\end{array}$ & 37 & 4,5 \\
\hline $\begin{array}{c}\text { Mosquetón } \\
\text { de posta }\end{array}$ & 5 onzas & 38 & 2,5 \\
\hline $\begin{array}{l}\text { Mosquete } \\
\text { ordinario }\end{array}$ & $\begin{array}{c}2,5 \text { onzas o } \\
3 \text { onzas (de } \\
\text { plomo) }\end{array}$ & 39 & $\begin{array}{c}\text { 1q y } 30 \\
\text { libras }\end{array}$ \\
\hline Arcabuz & $\begin{array}{c}1 \text { onza y } 4 \\
\text { adarmas o } 1 \\
\text { onza y } 10 \\
\text { adarmes (de } \\
\text { plomo) }\end{array}$ & 40 & 81 libras \\
\hline \multicolumn{4}{|c|}{ Segundo género: Cañones } \\
\hline Nombre & $\begin{array}{c}\text { Calibre } \\
\text { (bala de } \\
\text { hierro) }\end{array}$ & $\begin{array}{l}\text { Diáme- } \\
\text { tros }\end{array}$ & $\begin{array}{c}\text { Peso } \\
\text { (Quintales) }\end{array}$ \\
\hline $\begin{array}{c}\text { Cañón } \\
\text { doble, des- } \\
\text { pertador o } \\
\text { quebranta- } \\
\text { muros }\end{array}$ & 96 libras & 17 & 128 \\
\hline $\begin{array}{l}\text { Bate muros } \\
\text { o cañón } \\
\text { común de } \\
\text { batería }\end{array}$ & 48 libras & 18 & 72 \\
\hline $\begin{array}{l}\text { Brecante o } \\
\text { medio cañón }\end{array}$ & 24 libras & 19 & 43 \\
\hline $\begin{array}{l}\text { Quarto de } \\
\text { cañón, } \\
\text { perseguidor } \\
\text { o moyana }\end{array}$ & 12 libras & 24 & 27 \\
\hline $\begin{array}{l}\text { Octavo de } \\
\text { cañón }\end{array}$ & 6 libras & 27 & 21 \\
\hline
\end{tabular}

Finalmente destacamos la figura de Julio Cesar Firrufino, ingeniero y matemático español que ocupó un puesto destacado como catedrático de geometría y fortificación. Es autor de dos obras fundamentales para el estudio de la artillería. La primera se publicó en 1626 bajo el título de Platica Manual y Breve Compendio de Artilleria. Posteriormente, en 1648 vio la luz El perfecto artillero thorica y practica. Esta obra se finalizó hacia 1626, pero según Díaz Moreno «el Consejo de Estado prohibió su publicación aduciendo que desvelaba secretos y nuevas máquinas útiles a los enemigos de la Monarquía» (Díaz, 2000: 181). Esto corrobora que el hermetismo no era característico solo de los artesanos fundidores, sino también de la propia monarquía que amparaba este comportamiento, recelosa de otras naciones que actuaban de la misma manera. Respecto a la clasificación de la artillería, Firrufino consolida los tres géneros y las piezas que los constituyen y afirma que: «Siendo que para este conocimiento ha avido entre los Autores grande confusion; porque de nombrarlas impropiamente se viene a incurrir en un error notable y peligroso, en razon de la carga que le toca» (Firrufino, 1648: 103).

Tabla 5. Clasificación de las piezas de artillería según Julio César Firrufino (1648). Elaboración propia a partir de los datos extraídos de su obra El perfecto artillero theorica y practica.

\begin{tabular}{|c|c|c|}
\hline \multicolumn{3}{|c|}{ Primer género: Culebrinas } \\
\hline Nombre & $\begin{array}{c}\text { Calibre } \\
\text { (bala de hierro) }\end{array}$ & Diámetros \\
\hline Falconete & De 2 a 4 libras & - \\
\hline Sacre & 6 libras & - \\
\hline $\begin{array}{l}\text { Media Cule- } \\
\text { brina }\end{array}$ & De 8 a 12 libras & - \\
\hline Culebrina & De 15 a 25 libras & - \\
\hline \multicolumn{3}{|c|}{ Segundo género: Cañones } \\
\hline Nombre & $\begin{array}{c}\text { Calibre } \\
\text { (bala de hierro) }\end{array}$ & Diámetros \\
\hline Cañón & 25 libras & 18 \\
\hline Medio cañón & De 16 a 25 libras & $17-21$ \\
\hline $\begin{array}{l}\text { Tercio de } \\
\text { cañón }\end{array}$ & De 10 a 13 libras & 18 \\
\hline $\begin{array}{l}\text { Cuarto de } \\
\text { cañón }\end{array}$ & - & - \\
\hline \multicolumn{3}{|c|}{ Tercer género: Pedreros } \\
\hline Nombre & $\begin{array}{c}\text { Calibre } \\
\text { (libras de bala } \\
\text { de piedra) }\end{array}$ & Diámetros \\
\hline Cañón & De 19 a 40 & $12-14$ \\
\hline Medio cañón & De 13 a 18 & $12-14$ \\
\hline $\begin{array}{l}\text { Tercio de } \\
\text { cañón }\end{array}$ & De 6 a 10 & $12-14$ \\
\hline $\begin{array}{l}\text { Cuarto de } \\
\text { cañón }\end{array}$ & 12 & $12-14$ \\
\hline Morterete & $\geq 40$ & 22 \\
\hline
\end{tabular}




\section{ORIGEN Y DESTINO DE LA ARTILLERÍA ALMACENADA EN LA MERCEDES}

En 1804 el marqués de Avilés, virrey del Perú, aprovechando el viaje que las cuatro fragatas de la Real Armada estaban realizando por América en búsqueda de caudales que pudieran paliar la bancarrota española, comunica a Miguel Cayetano Soler, secretario de Estado y del Despacho de Hacienda, que se hallan en la plaza del Callao 10 cañones de bronce inútiles y que las fragatas que allí se encuentran los podrían transportar hasta España sin coste alguno para su aprovechamiento ${ }^{1}$. El 28 de marzo de 1804 embarcaron con destino a Cádiz: la fragata Asunción cargó de cuenta del rey «4 cañones de bronce inútiles» ${ }^{2}$, la Santa Clara embarcó el mismo número ${ }^{3}$ que la anterior y por último, la Mercedes solo «2 cañones de bronce inútiles» ${ }^{4}$. Finalmente se decide (por causas que aún desconocemos) el embarque únicamente de 6 cañones, dos en cada buque ${ }^{5}$.

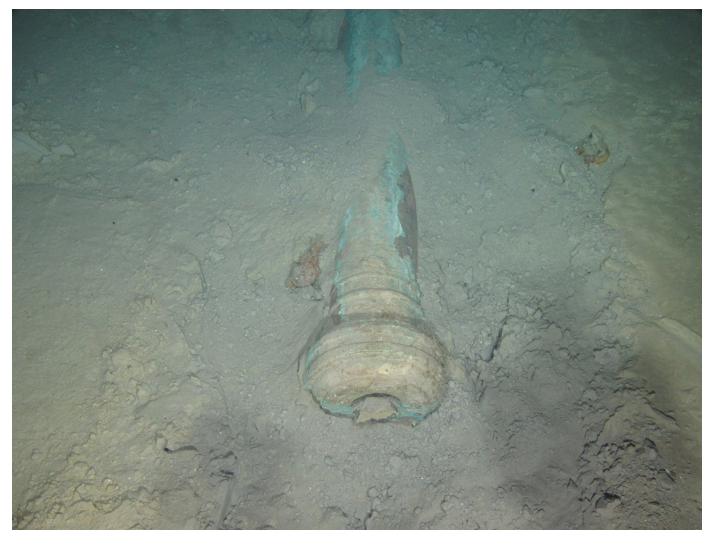

Figura 2. Situación de la caña y brocal de la culebrina llamada Santa Bárbara en los instantes previos a su excavación y recuperación. (C) Archivo Museo Nacional de Arqueología Subacuática / Instituto Español de Oceanografía.
1 AGI, LIMA, 1440, N. 25-75.

2 AGI, LIMA, 1440, N. 25-67.

3 AGI, LIMA, 1440, N. 25-71.

${ }^{4}$ AGI, LIMA, 1440, N. 69-84.

${ }_{5}$ Tras llegar el 5 de junio de 1804 a Montevideo, la fragata Asunción a consecuencia de los fuertes temporales que sufrió al pasar el cabo de Hornos, tuvo que traspasar su carga a la Medea, ante la imposibilidad de continuar con el viaje. Archivo General de Indias, LIMA, 1440, N. 30-5.
Sobre la identidad de estos cañones, un estado de fuerza y vida perteneciente a la fragata Mercedes, fechado en Montevideo el 5 de junio de 1804 y rubricado por José Goycoa, señala que en sus bodegas se encuentran «dos culebrinas excluidas de bronce» ${ }^{6}$. Un documento similar firmado por Diego de Alesón, comandante de la Clara, señala que entre su carga, junto a los minerales (cobre y estaño), se encuentran «140 quintales de la misma especie en dos culebrinas de bronce en quatro trozos» (O’Donnell, 2013: 84). Respecto a los cañones que transportaba en un principio la Asunción y que posteriormente fueron embarcados en la $\mathrm{Me}$ dea, no hemos encontrado ninguna otra mención.

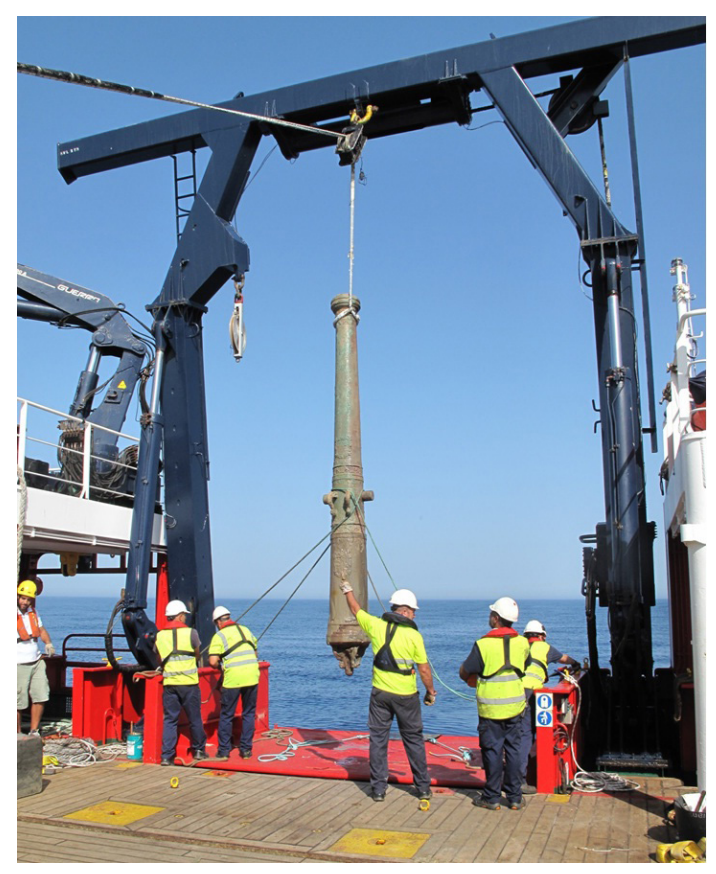

Figura 3. Instante en el que una de las dos culebrinas recuperadas del yacimiento llega a la cubierta del buque Sarmiento de Gamboa. (C) Archivo Museo Nacional de Arqueología Subacuática / Instituto Español de Oceanografía.

Algunos autores afirman que el destino de las piezas que cargaban la Clara y la Medea era el posterior aprovechamiento del metal, pero, para las estibadas en la Mercedes sería: «Integrarse en

\footnotetext{
${ }^{6}$ BRAH, Col. JPG, ms. 11/8305. Extraído de José Ignacio González- Aller Hierro (2004): La campaña de Trafalgar (1804-1805). Tomo I. Ministerio de Defensa. Armada Española. Madrid.
} 
las colecciones reales, como recuerdo histórico de una época gloriosa en que el marqués de Guadalcázar, virrey del Perú, las hiciera fundir para proteger El Callao de la amenaza holandesa de L'Hermite» (O’Donnell, 2013: 93).

La hipótesis que mantenemos es que la artillería excluida que transportaban las tres fragatas tenía como destino servir de materia prima en las fundiciones peninsulares, posiblemente en la de Sevilla. Tras la guerra anglo-española (17961802), el tráfico marítimo con América se interrumpió, por lo que la llegada de caudales a España se redujo. Aprovechando la firma de la Paz de Amiens (1802), la Secretaria de Estado y de Despacho de Hacienda ordenó a los virreyes de Nueva España, Río de la Plata y Perú que aglutinasen todos los recursos posibles para intentar sanear las maltrechas arcas de la Real Hacienda. ${ }^{7}$ Además del cargamento de plata, lana o cascarilla, destaca el de cobre y estaño ${ }^{8}$, materiales básicos para elaborar artillería de bronce, por lo que a estas cantidades se suman los cañones inútiles.

Tabla 6. Elaboración propia a partir del Estado general de los caudales y efectos que conducen las fragatas de guerra de la división al mando de D. Joseph de Bustamante y Guerra, Jefe de Escuadra de la Real Armada. Archivo General de Simancas, EST, LEG, 8283, 13-001.

\begin{tabular}{|c|c|c|c|}
\hline Buques & $\begin{array}{c}\text { Lingotes } \\
\text { de } \\
\text { estaño }\end{array}$ & $\begin{array}{c}\text { Lingotes } \\
\text { de cobre }\end{array}$ & $\begin{array}{c}\text { Peso total del } \\
\text { cobre y estaño }\end{array}$ \\
\hline Medea & 1627 & 203 & $55600,24 \mathrm{~kg}$ \\
\hline Fama & 300 & - & $6756 \mathrm{~kg}$ \\
\hline Mercedes & 1139 & 961 & $115407,68 \mathrm{~kg}$ \\
\hline Clara & 1666 & 571 & $90849,72 \mathrm{~kg}$ \\
\hline Total & $\mathbf{4 7 3 2}$ & $\mathbf{1 7 3 5}$ & $\mathbf{2 6 8 6 1 3 , 6 4} \mathbf{~ k g}$ \\
\hline
\end{tabular}

${ }^{7}$ AGI, INDIFERENTE, 1348, N. 1-2.

${ }^{8}$ En ARQVA se conservan dos lingotes de estaño procedentes del pecio de la Mercedes. Uno de ellos, con el número de inventario NSMS-5150 pesa $28,16 \mathrm{~kg}$ y el otro (NSMS$5151) 16,88 \mathrm{~kg}$. Consideramos la media de las dos cifras para hacer un cálculo aproximado del peso medio de un lingote de estaño que equivaldría a $22,52 \mathrm{~kg}$. También se conservan otros cinco de cobre: NSMS-5145 (peso: 85,01 kg), NSMS-5146 (peso: 90,78 kg), NSMS-5147 (peso: 80,94 kg), NSMS-5148 (peso: $115,5 \mathrm{~kg}$ ) y NSMS-5149 (peso: $94,88 \mathrm{~kg}$ ). Partiendo de estas cifras, el peso medio de un galápago de cobre rondaría los $93,4 \mathrm{~kg}$.
La escasez en España de cobre y estaño y la necesidad de custodiar las rutas marítimas hizo que la repatriación de artillería de bronce antigua o dañada fuese una actividad constante. Esta artillería, entre sus muchas bondades, destaca porque tras su continuado uso se puede volver a fundir para obtener una pieza nueva (García-Torralba, 2010). Esta forma de proceder era muy estimada por su fácil trabajo. Las piezas obtenidas mediante la fundición de cañones viejos e inservibles reciben el nombre de metal ligado (Serrano Mangas, 1989: 130).

La urgencia de fundir gran cantidad de artillería para defender las flotas americanas, los presidios ultramarinos y el resto de empresas de la Corona, hizo que el Consejo de Indias, en 1596, ordenase que:

En las flotas se traya por lastre toda la mayor cantidad de cobre que se pudiere, aunque no esté adulçado en la perfeccion que se requiere, pues acá se podrá remediar esa falta, y es mas conveniente que las fundiciones se hagan aquí y que se envie con las flotas la artillería que alla fuera menester, pues esta forma yran las flotas mas bien artilladas de aquí .

Repatriar artillería desde el virreinato del Perú fue habitual, lo demuestran numerosos documentos custodiados en el Archivo General de Indias. Sirva de ejemplo la correspondencia mantenida en 1786 entre Teodoro de Croix, virrey del Perú y José Gálvez, Secretario de Indias sobre las peticiones que el presidente de la Casa de la Contratación de Cádiz le hacía sobre la necesidad de: «Remitirle cañones, morteros y pedreros de bronce, que en la verdadera clase de inutiles existan en los Puertos y Almacenes de la comprension de este Virreynato» ${ }^{10}$.

El virrey le contesta que ya despachó en el «navío del Rey nombrado Santiago la América cobres viejos de errages de cureñas inútiles y cobres nuevos en barras $\rangle^{11}$. También le informa de que:

En la Plaza del Callao han quedado varios cañones y pedreros de bronce antiguos en la clase de medianos por tener algun servicio, sin embargo que en realidad no ay tal clase y deben contarse por inutiles, representó en aquel entonces se mantuviesen en otra Plaza por no dejarla indefensa hasta que ven-

\footnotetext{
${ }^{9}$ AGI, INDIFERENTE, 744, N.55.

10 AGI, LIMA, 696, N.22.

${ }^{11}$ AGI, LIMA, 696, N.22.
} 
gan de España otros con que se pudiere remediar del todo la suma falta que hacían, y que verificado este caso no solo se remitirán a Europa los referidos cañones, sino también los antiguos de Bronce que permanecen en Guayaquil, Islas de Chiloe, Juan Fernandez y demás Provincias de este Virreynato ${ }^{12}$.

\section{IDENTIFICACIÓN Y ESTUDIO DE LAS PIEZAS DE ARTILLERÍA RECUPERADAS}

El 29 de agosto de 2017, concluida la tercera campaña arqueológica, ingresaron en los laboratorios de conservación y restauración del museo ARQVA, entre otros objetos, dos piezas de artillería de gran tamaño. Recibieron respectivamente los números de inventario NSMS17-00001 y NSMS17-00002 y se inició un exhaustivo tratamiento de estabilización por decloruración; operación imprescindible para mantener la integridad de las piezas y asegurar su perfecto estado de conservación (Gil, 2001).

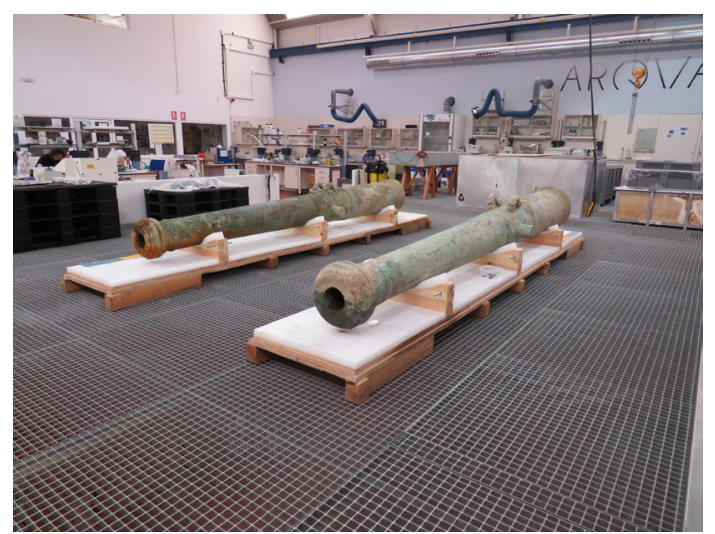

Figura 4. Llegada de las dos piezas de artillería a ARQVAtec para iniciar los trabajos de estudio, conservación y restauración. (CArchivo Museo

Nacional de Arqueología Subacuática / Juan Jesús Oliver Laso

Tras la toma de muestras, medidas y fotografías se procedió a la limpieza mecánica de ambos cañones. Se analizaron las dos ánimas y se extrajo gran cantidad de limo procedente del fondo marino. Se comprobó que ambas recámaras estaban bloqueadas por cantos rodados (lastre del buque)

\footnotetext{
${ }^{12}$ AGI, LIMA, 696, N.22.
}

y se procedió a su extracción. En la pieza NSM1700001, llamada Santa Bárbara, aparecieron de restos de madera (probablemente una caja), numerosos granos de cacao, algunos tallos vegetales, pelo de mediano tamaño y lo más sorprendente, los restos de una rata. Por último, se hallaron 23 reales de a ocho con restos adheridos de la saca donde iban acumuladas.

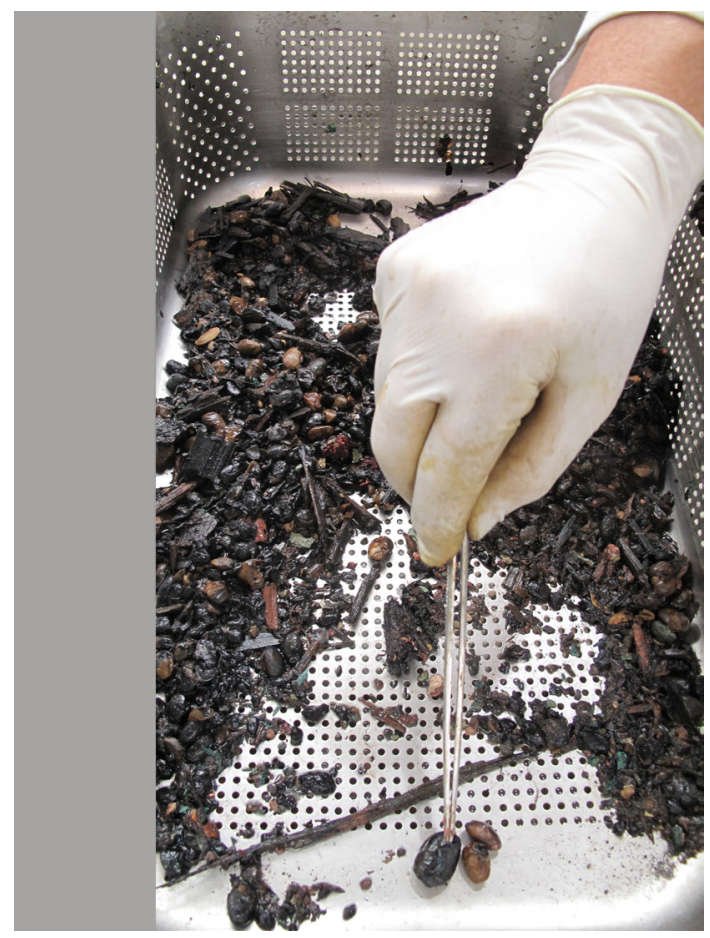

Figura 5. Proceso de recuperación de los restos orgánicos hallados en el interior de una de las piezas de artillería. (C) Archivo Museo Nacional de Arqueología Subacuática / Luis Ángel Torres Sobrino.

En la NSMS17-00002, llamada Santa Rufina, de su recámara se retiraron: piedras de lastre, restos de astillas, una pequeña cantidad de granos de cacao, así como restos de pelo y fibras vegetales pertenecientes al saquito donde iban ocho monedas de ocho reales que se extrajeron en perfecto estado de conservación.

La hipótesis que barajamos es que los materiales encontrados en el interior de ambos cañones fueran ocultados de manera intencional y fraudulenta por algún miembro de la tripulación, una vez estibada toda la mercancía, a modo de ilícito tesorillo, para ser recuperados en el puerto de destino. 


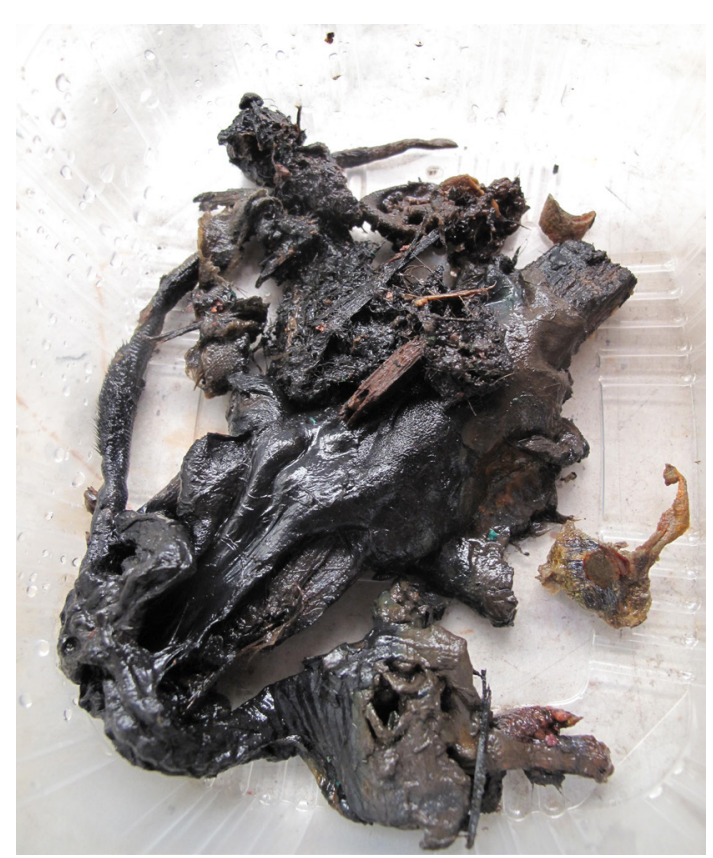

Figura 6. Restos del roedor encontrado en el ánima de la culebrina Santa Bárbara. (C) Archivo Museo Nacional de Arqueología Subacuática / Luis Ángel Torres Sobrino.

\subsection{DESCRIPCIÓN DE LAS PIEZAS}

\section{La culebrina llamada Santa Bárbara}

Es una boca de fuego elaborada en bronce mediante fundición. Esta técnica consiste en mezclar cobre y estaño en estado líquido para verterse en el interior de un molde de arcilla, previamente diseñado con las formas y medidas de la pieza que se desea obtener. Su longitud total es de 4,35 metros, desde el cascabel hasta el brocal.

Tabla 7. Peso y medidas de Santa Bárbara. Elaboración propia.

\begin{tabular}{|c|c|}
\hline Peso & $2663 \mathrm{~kg}$ \\
\hline Longitud total & $4,35 \mathrm{~m}$ \\
\hline Longitud sin la lámpara & $3,98 \mathrm{~m}$ \\
\hline Longitud del primer cuerpo & $1,12 \mathrm{~m}$ \\
\hline Longitud del segundo cuerpo & $0,64 \mathrm{~m}$ \\
\hline Longitud del tercer cuerpo & $2,22 \mathrm{~m}$ \\
\hline Longitud del ánima & $3,83 \mathrm{~m}$ \\
\hline Ancho (de muñón a muñón) & $0,56 \mathrm{~m}$ \\
\hline Calibre & $0,13 \mathrm{~m}$ \\
\hline
\end{tabular}

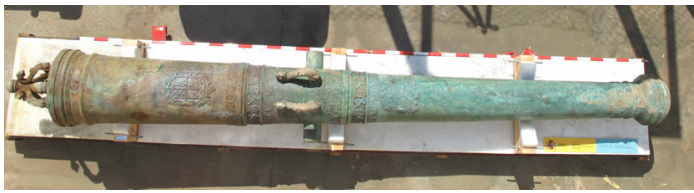

Figura 7. Fotografía general de la culebrina Santa Bárbara. (C) Archivo Museo Nacional de Arqueología Subacuática / Juan Luis Sierra Méndez.

En el cuello del cascabel de perfil abalaustrado, se disponen perimetralmente cuatro animales fantásticos de dos cabezas (salvo uno de ellos que presenta pérdida de material). En la lámpara encontramos tres orificios rectangulares dispuestos uno en cada extremo de la misma formando, si uniésemos los tres, un triángulo equilátero. Estas oquedades convergen en el interior de la lámpara, pero no llegan al ánima. Su finalidad era ajustar la pieza en la fundición para que el ánima y la culata quedasen centradas.

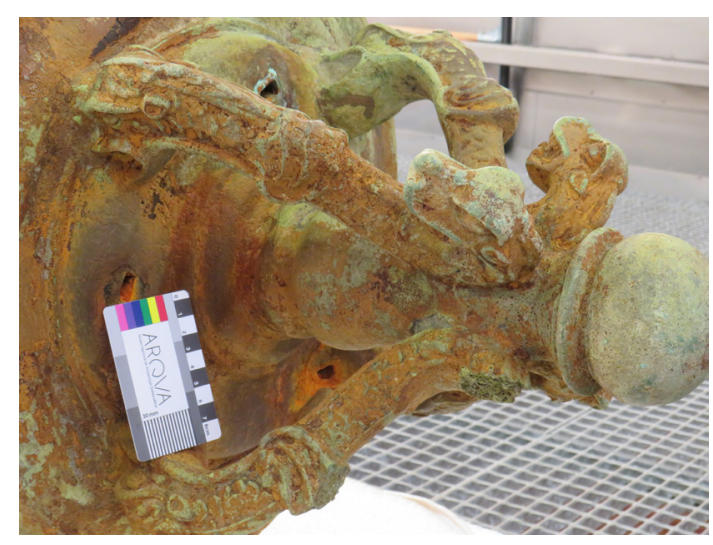

Figura 8. Detalle de parte de la lámpara y el cascabel ricamente decorado. (C) Archivo Museo Nacional de Arqueología Subacuática / Juan Jesús Oliver Laso.

A continuación, en la faja alta de culata encontramos la inscripción realizada a buril «58 Q I A», que nos indica el peso de la pieza: 58 quintales y una arroba. Esta cifra, partiendo de que un quintal castellano de la época son $46,0093 \mathrm{~kg}$ y una arroba $11,5023 \mathrm{~kg}$, equivaldría a $2679,5 \mathrm{~kg}, 16,5$ kilos de diferencia con respecto al peso tomado en el laboratorio (2663 kg). Posteriormente, en el fogón, localizamos un grano, es decir, una reparación común en la época que consistía en sustituir el oído deteriorado del uso por un elemento cilíndrico con un nuevo orificio. Esta reparación evi- 
dencia que la pieza realizó numerosos disparos; la ignición continuada de la pólvora ubicada en el fogón hizo que el bronce se fuera deteriorando hasta aumentar peligrosamente su diámetro. Junto al nuevo orificio se encuentra, en la parte inferior, un intento de grano pues solo se presenta su circunferencia y una leve hendidura ${ }^{13}$.

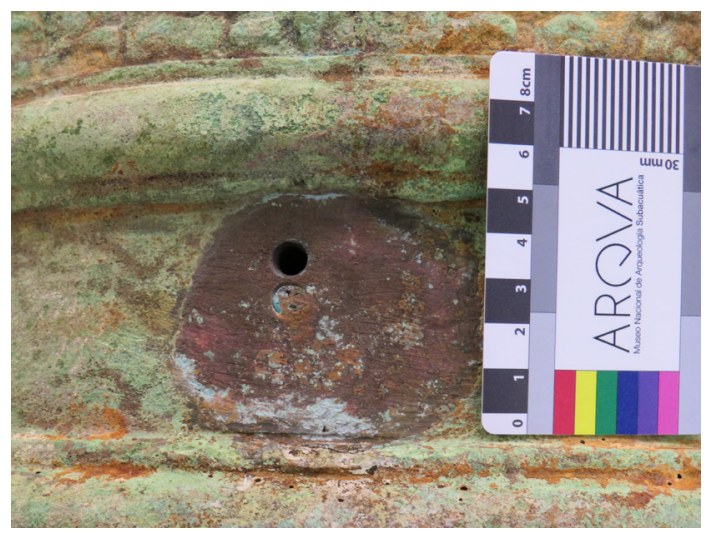

Figura 9. Grano practicado sobre el fogón de la culebrina Santa Bárbara como consecuencia de la dilatación de este tras realizar numerosos disparos. (C) Archivo Museo Nacional de Arqueología Subacuática / Juan Jesús Oliver Laso.

En el filete del primer cuerpo encontramos una cenefa perimetral (que se va a repetir al principio y final de los tres cuerpos) decorada con dos figuras humanas de cuerpo entero, tenantes y afrontadas dos a dos, que se disponen en torno a un jarrón central decorado con gallones y ovas, rodeado de volutas y rocalla. Según Plaza, Martínez y Vaquero, autores de la Guía para identificar los personajes de la mitología clásica (2016), la decoración de esta cenefa se asemeja a las composiciones renacentistas en las que se mostraban figuras de estilo grutesco (posiblemente tritones o titanes) que representan una alegoría marina junto a un jarrón que podría simbolizar una fuente de agua (fuente de la vida). En la parte central del primer cuerpo encontramos un escudo con las armas de León y Castilla y en punta las de Granada, con corona real y adornado con lambrequines. Por

${ }^{13}$ Se aprecia la precariedad del método empleado ya que el nuevo fogón no está centrado con respecto a la pieza cilíndrica que se instaló, además, debajo de este nuevo orificio se aprecia el inicio de la perforación de otro que posiblemente no se encontraba en el lugar deseado. último, aparecen en los laterales de este cuerpo varias oquedades que en la fundición se usaban para ajustar el molde a la pieza resultante, centrando el ánima mediante varas de hierro que serían retiradas posteriormente.

En el segundo cuerpo encontramos, además de una faja y la cenefa anteriormente descrita, que se repite tanto al principio como al final del mismo, otra que presenta un león pasante hacia la izquierda, apoyado en el lateral de un castillo, que constituyen las armas de Castilla y León. En el centro aparecen dos asas paralelas o delfines que adoptan la forma de un dragón (son distintivos de cada fundidor). Su misión era sostener la pieza cuando esta se alzaba para su transporte o colocación. A continuación, encontramos en letras capitales «SANTA BARBARA», nombre de la pieza y advocación a la patrona de la artillería como azote del hereje y defensora de la cristiandad. En los laterales del segundo cuerpo localizamos dos muñones cilíndricos centrados respecto al eje longitudinal de la pieza, por lo que estando colocada sobre su cureña quedaría ligeramente hundida, mejorando la capacidad de esta para absorber el

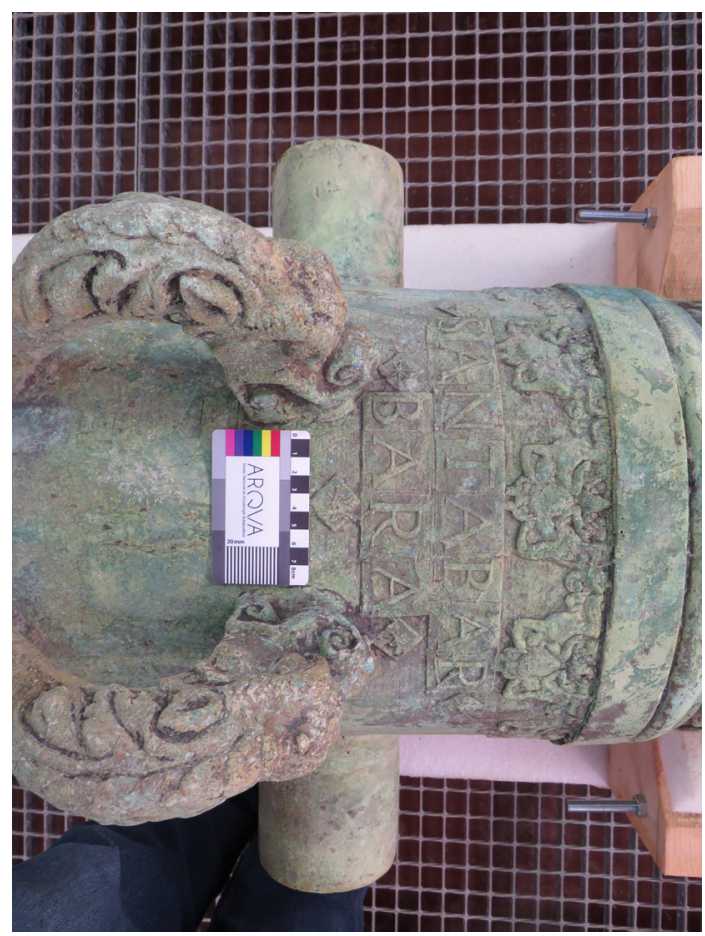

Figura 10. Advocación en letras capitales de una de las piezas de artillería a Santa Bárbara. (C) Archivo Museo Nacional de Arqueología Subacuática / Juan Jesús Oliver Laso. 
retroceso, pero dificultando la tarea de hacer puntería al artillero. Por último, encontramos otra cenefa con figuras tenantes y una faja.

La caña se inicia con dos fajas que repiten la misma decoración del segundo cuerpo. A continuación encontramos, inscrito en el interior de un escudo la identidad de la persona que ordena la elaboración de la pieza: «PORMA/DADODE(letra enlazada)/LECX(superada de O)S(superada de $\mathrm{R}) \mathrm{C}$ (con $\mathrm{O}$ inscrita)/DE(letra enlazada)DE(letra enlazada)LVI/LLAR» (POR MANDADO DEL EXCELENTÍSIMO SEÑOR CONDE DEL VILLAR). En la zona del cuello hay dos cenefas con las mismas figuras tenantes y en el centro una faja donde leemos: «1586 BERNARDINO DE TEJEDA ME FECIT». Esta nos indica cuando se fundió y quien la realizó. Por último, el brocal presenta un tamaño superior al resto de la pieza para actuar como refuerzo en el momento de expulsar la bala. En esta zona se ha constatado una importante pérdida de material como consecuencia del reiterado uso de la pieza.

Respecto a su ánima, empleando un endoscopio, se descubrieron y analizaron los daños in-

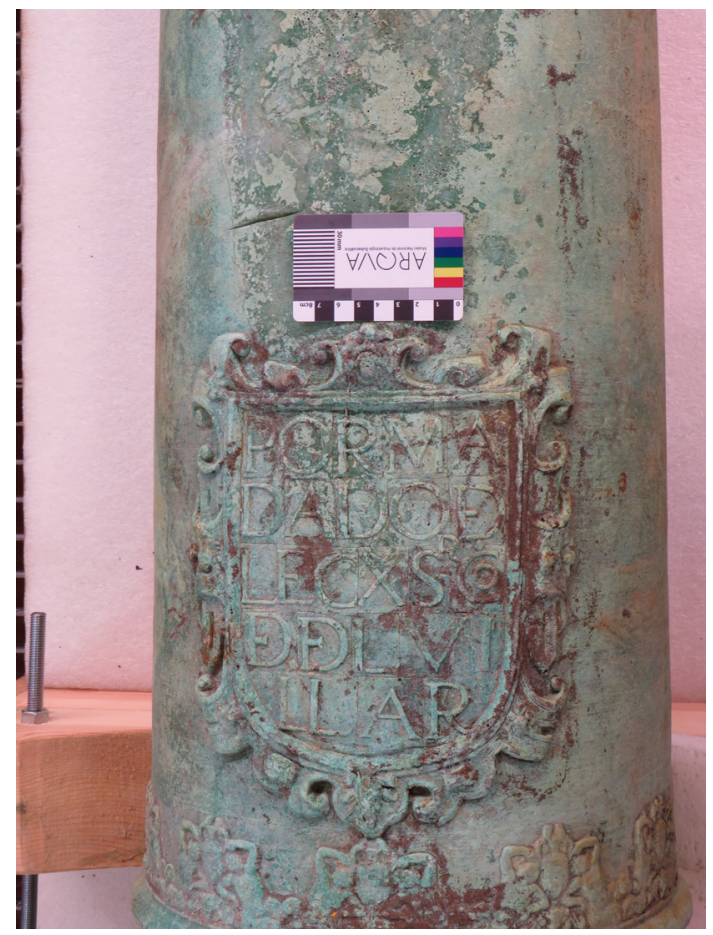

Figura 11. Escudo con lambrequines en honor a don Fernando de Torres y Portugal, VII Virrey del Perú. (C) Archivo Museo Nacional de Arqueología Subacuática / Juan Jesús Oliver Laso. ternos. Se confirmó la presencia de importantes «escarabajos», es decir, significativas oquedades o hendiduras que provocaron el desempleo de la pieza y que según Rovira se producían por:

Impuridades ó porosidades del metal, desconchaduras causadas de gotas frias del mismo metal derretido al tiempo de congelarse, rebolladuras originadas de la vibración del hasta de la barrena, incisiones y surcos de los alambras con que se sujetan los barros del ánima: y si es Pieza que ha disparado, suele tener hoyos del resalto de las balas (Rovira, 1773: 154).

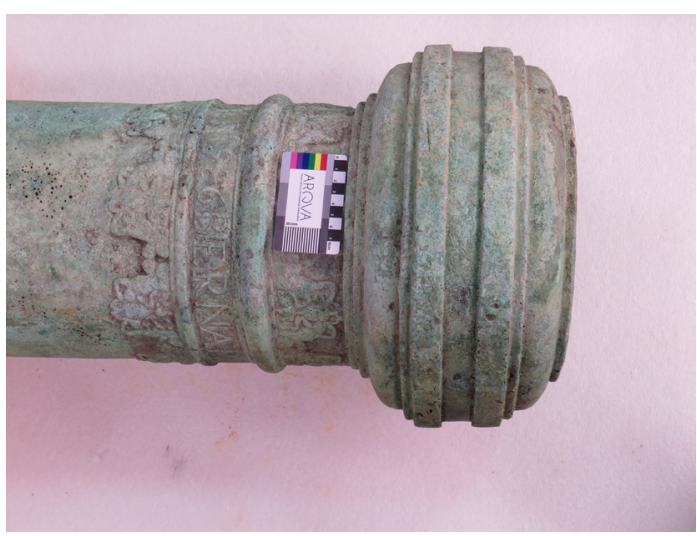

Figura 12. Brocal de la culebrina Santa Barbara. (C) Archivo Museo Nacional de Arqueología Subacuática / Juan Jesús Oliver Laso.

En cuanto a su calibre, partiendo de que el diámetro de su ánima es de $13 \mathrm{~cm}$, los proyectiles que disparaba eran esféricos y de hierro y que en siglo XVI y XVII el calibre se expresaba en función del peso de la bala (libras castellanas), este sería de 19 libras, considerando el viento, lo que equivaldría a unos $8,87 \mathrm{~kg}$ de proyectil. Si atendemos a las clasificaciones hechas por los artilleros de la época, podemos afirmar que por su longitud y calibre pertenecería al género las culebrinas, es más, se trataría de una media culebrina, pues sus medidas concuerdan con las expresadas para este tipo según Diego de Alaba y Luis Collado

\section{La culebrina nombrada Santa Rufina}

Elaborada también en bronce fundido, su longitud total es de 3,90 metros. Su cascabel es abalaustrado y sencillo. En la faja alta de culata, encontramos inscrito a buril el peso de la pieza: «46 Q 2 A». Estos 46 quintales y dos arrobas equi- 
valen a unos $2139,43 \mathrm{~kg}$, cifra cercana a los 2214 $\mathrm{kg}$ obtenidos pesando la pieza en el laboratorio. A continuación, en el campo del fogón encontramos un grano que como ocurría en la pieza anterior, demuestra la necesidad de mantener el cañón en servicio, ante la necesidad de artillería y la imposibilidad de refundir la pieza.

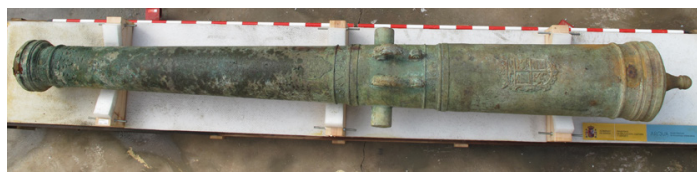

Figura 13. Fotografía general de la boca de fuego llamada Santa Rufina. (C) Archivo Museo Nacional de Arqueología Subacuática / Juan Luis Sierra Méndez.

Tabla 8. Peso y medidas de Santa Rufina. Elaboración propia.

\begin{tabular}{|c|c|}
\hline Peso & $2214 \mathrm{~kg}$ \\
\hline Longitud total & $3,90 \mathrm{~m}$ \\
\hline Longitud sin la lámpara & $3,65 \mathrm{~m}$ \\
\hline Longitud del primer cuerpo & $1,13 \mathrm{~m}$ \\
\hline Longitud del segundo cuerpo & $0,49 \mathrm{~m}$ \\
\hline Longitud del tercer cuerpo & $2,03 \mathrm{~m}$ \\
\hline Longitud del ánima & $3,5 \mathrm{~m}$ \\
\hline Ancho (de muñón a muñón) & $0,52 \mathrm{~m}$ \\
\hline Calibre & $0,12 \mathrm{~m}$ \\
\hline
\end{tabular}

En el primer cuerpo encontramos un escudo de España idéntico al de Santa Bárbara, así como una serie de orificios circulares empleados durante su fundición. Tras la faja que refuerza y separa este cuerpo del segundo encontramos entre dos rombos la cifra «1601» que se corresponde con el año de su elaboración. También hay dos asas decoradas igual que las de la anterior pieza ${ }^{14}$. Bajo estas se descubren los muñones, ubicados por debajo del eje longitudinal de la pieza, lo que se traduce en una mejor posición para hacer puntería, pero un mayor esfuerzo para las gualderas de la cureña, que soportan el efecto del retroceso en una posición más elevada generando mayor deterioro.

Por último, en la parte inferior del tercer cuerpo, encontramos entre un filete y una faja que refuerzan la pieza, «S. RVFINA» (entre dos

\footnotetext{
${ }^{14}$ Las asas constituían una seña de identidad de cada fundidor y en ambas piezas presentan idéntica morfología.
}

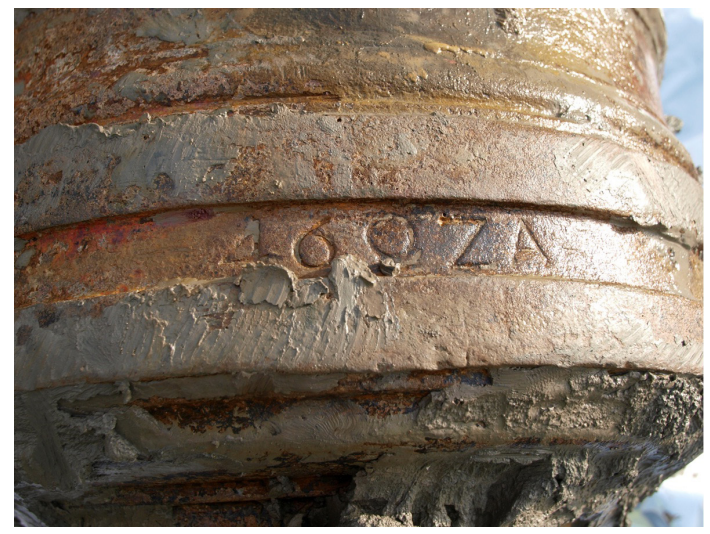

Figura 14. Detalle de la faja alta de culata de la culebrina Santa Rufina donde se observa el peso de la pieza: «46 Q 2 A». (C) Archivo Museo Nacional de Arqueología Subacuática / Juan Luis Sierra Méndez.

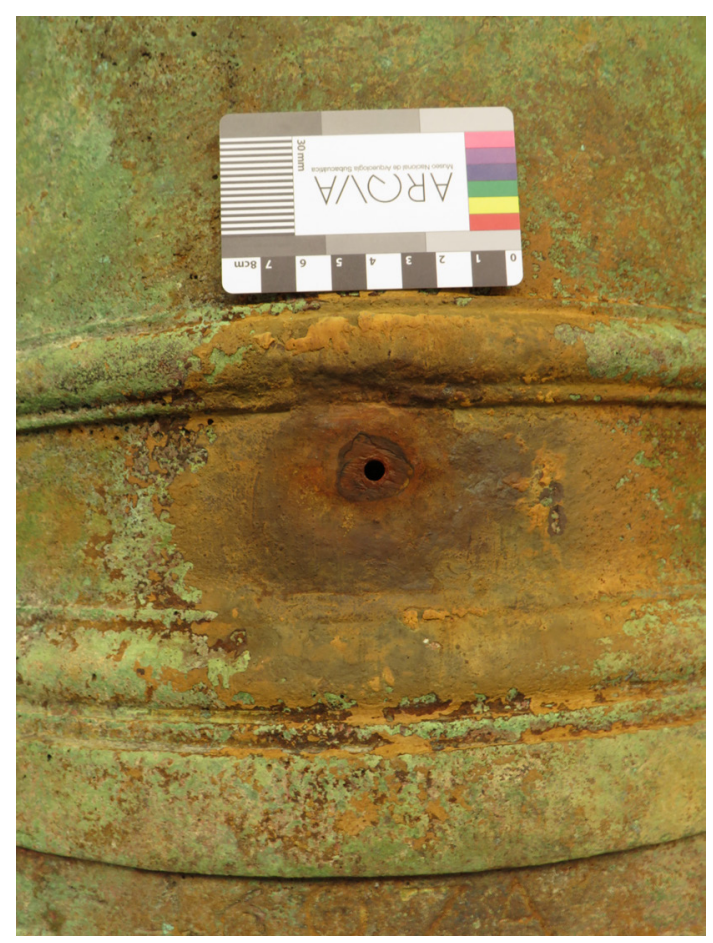

Figura 15. Reparación efectuada sobre el fogón de la pieza empleando un grano. (C) Archivo Museo Nacional de Arqueología Subacuática / Juan Jesús Oliver Laso.

rombos), traducido como, Santa Rufina. La advocación a esta mártir, probablemente se debe a que el fundidor procedía de Sevilla, de la cual esta es patrona. Junto a dicho nombre hay jaquelado un escudo de armas perteneciente a don Luís de Velasco y Castilla, virrey del Perú entre los años 
1596 y 1604 (Soler, 2009). Este noble fue quien mandó fabricar el cañón. Cerca del brocal encontramos decoración vegetal (hojas de acanto) que rodea perimetralmente el cuello de la pieza, como si de una columna corintia se tratase. En el papo de paloma se puede leer «BERNARDINO DE TEXEDA», nombre y apellido del fundidor que la hizo. Finalmente, el brocal posee mayor grosor y una serie de molduras que refuerzan esta parte.

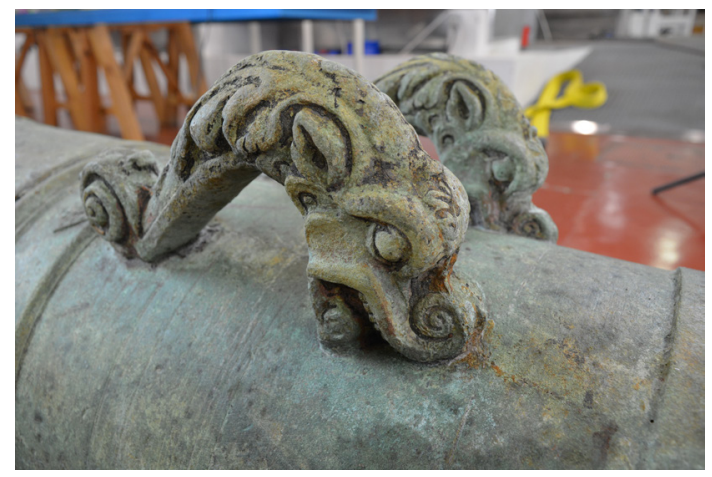

Figura 16. Delfines o asas decoradas con motivos mitológicos. (C) Archivo Museo Nacional de Arqueología Subacuática / Luis Ángel Torres Sobrino.

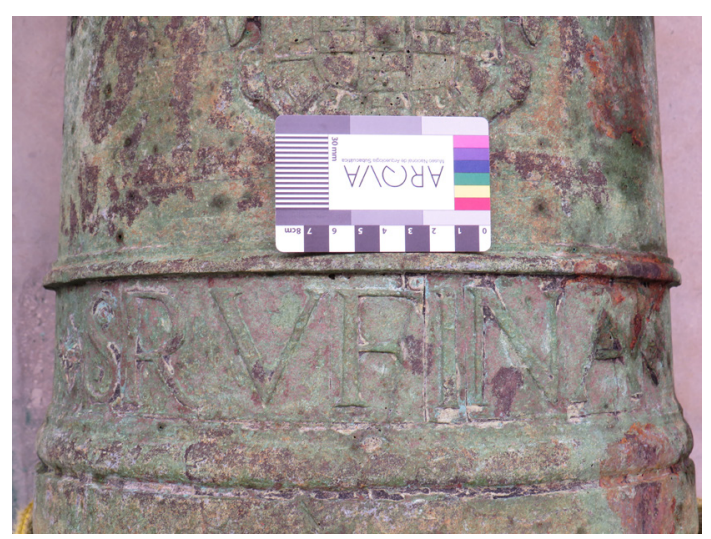

Figura 17. En la parte baja del tercer cuerpo de uno de los cañones se puede leer en letras capitales: «S. RVFINA», advocación que da nombre a la pieza y amparo espiritual a los servidores que la manejaban.

(C) Archivo Museo Nacional de Arqueología Subacuática / Juan Jesús Oliver Laso.

Al igual que ocurría con la otra pieza, esta también presenta importantes deterioros en su ánima, tanto en su parte interior en forma de «escarabajos», como en el brocal, donde se observan una serie de muescas generadas por la combustión de la pólvora en los disparos.

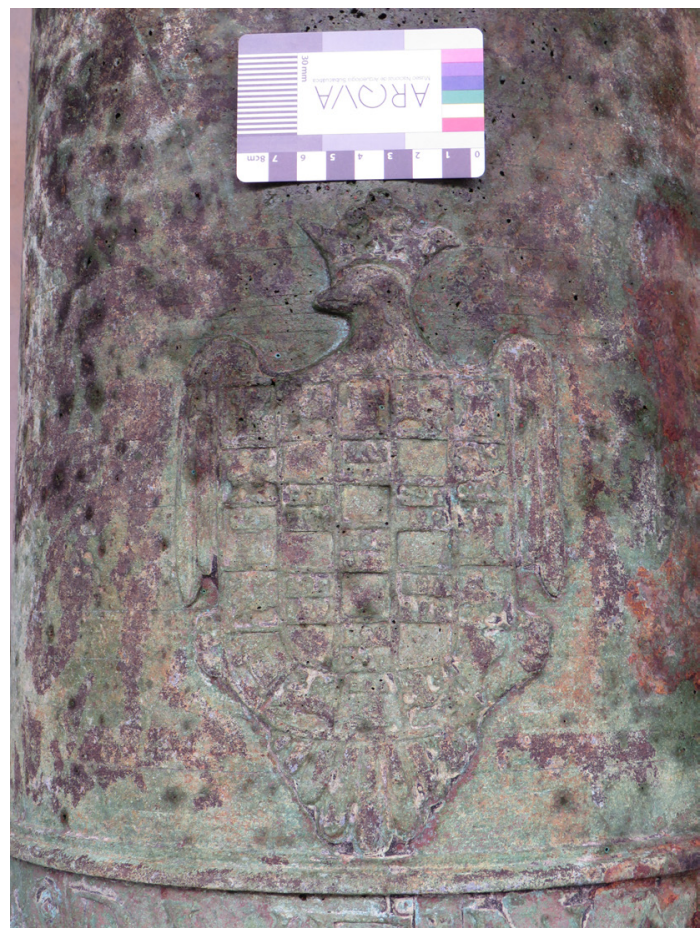

Figura 18. Escudo de armas de don Luis de Velasco y Castilla, IX Virrey del Perú. (C) Archivo Museo Nacional de Arqueología Subacuática/ Juan Jesús Oliver Laso.

Respecto al calibre, el diámetro de su ánima es de $12 \mathrm{~cm}$ y este se expresa según el peso de la bala, en libras castellanas, es decir, sería de a 15 libras (teniendo en cuenta el viento). Supondría unos $7 \mathrm{~kg}$ de proyectil. Comparando estos resultados con las medidas ofrecidas por los autores de

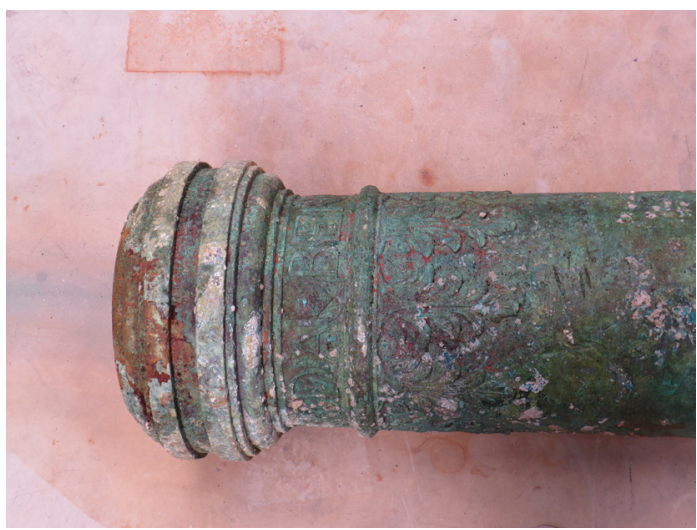

Figura 19. Brocal adornado con hojas de acanto perteneciente a la culebrina Santa Rufina. (C) Archivo Museo Nacional de Arqueología Subacuática / Juan Jesús Oliver Laso. 
la época, obviamente se trataría de una pieza comprendida en el género culebrinas y al igual que ocurría con Santa Bárbara, si tenemos en cuenta a Luis Collado y Diego de Alaba, se trataría de una media culebrina.

\section{UN ARTÍFICE SEVILLANO EN LA CIUDAD DE LOS REYES}

El padre Buenaventura de Salinas en su $M e$ morial de las historias del Nuevo Mundo. Perv de 1631, se refirió a las defensas del puerto del Callao enumerando uno por uno los fuertes de esta plaza. De estos destacaba que se encontraban «guarnecidos cada vno con grandes pieças, y culebrinas Reales de bronze, el mexor, y mas bien labradas y vaziadas, que tiene el vniverso, por ser aquellos Reynos abundantissimos de bronze, y auer tenido por su escogido Artifice a Texeda». Ahora bien, ¿quién era Tejeda? Gracias a las investigaciones de Rosa Pérez Canepa tenemos una sucinta semblanza de este artífice (Pérez, 1946). Aunque adolece de información de sus años iniciales, cabe suponer que su nacimiento se produjo ya entrada la segunda mitad del siglo xvi y que pudo principiarse en las técnicas de fundición bajo tutela paterna. Todo parece indicar que su padre, Francisco Jiménez de Tejeda, se estableció en Sevilla y debió ejercer también como fundidor ${ }^{15}$, pues así nos lo indica el expediente de información y licencia de pasajeros a Indias de su hija, Cristina de Tejeda acompañada por su marido Fernando de Flores y las hijas del matrimonio, Catalina y Ana, todos originarios de la capital hispalense, el 5 de noviembre de $1607^{16}$. Desconocemos si alguno de los dos, padre e hijo, tuvo relación con el originario taller de fundición de bronces de $\mathrm{Se}$ villa, establecido por el maestro Juan Morel en el barrio de San Bernardo (Vega, 1992). Pero resulta incuestionable que Bernardino de Tejeda, además

15 En este sentido hallamos una posible referencia a Francisco Jiménez en el tomo III del Ensayo de un diccionario de los artifices que florecieron en Sevilla desde el siglo XIII al XVIIII inclusive de José Gestoso y Pérez. En dicha obra se menciona que fue vecino de la colación de San Salvador. El 20 de septiembre de 1557, junto con Antonio de Plasencia, «se concertaron por dos años para hacer en compañía todas las campanas chicas y grandes que les encargasen, sin que pudiesen facilitar moldes para que otro oficial las hiciera; partiendo las ganancias por la mitad» (Gestoso, 1889: III, 75).

${ }_{16}$ Fernando de Flores. AGI, Contratación, 5299, N. 1, R. 69. 5-XI-1607. de ser experto en la fundición de bronces, demostró interés por otros campos como la arquitectura y la ingeniería, materias sobre las que debía de tener nociones muy asentadas. Esto quedó evidenciado cuando tanto el Cabildo de Lima como las autoridades virreinales solicitaron su dictamen o su intervención sobre estas materias y en múltiples ocasiones (Lohmann, 1949: 219).

Fuentes contemporáneas mencionan a Tejeda como «hombre rico y de buena traza e ingenio como es notorio» (Pérez, 1946: 20) y de principios de siglo datan las impresiones recogidas en la Descripción anónima del Perú y de Lima a principios del siglo XVII, atribuida al portugués Pedro de León Portocarrero, donde se recoge que en el Callao «estaban siempre las naves de guerra Capitana y Almiranta, con artillería de bronce fundida en Lima por el maestro Juan Bernardino de Tejada que tenía su oficina junto a San Agustín» (Riva, 1914: 364-365). La documentación de este periodo deja patente además sus vínculos con determinadas comunidades religiosas ${ }^{17} \mathrm{y}$ con el Real Hospital de San Andrés, del que fue mayordomo hasta en dos ocasiones, y su participación en algunas actividades navieras, como armador. Existe constancia documental de que era propietario de un navío que debió naufragar en el área de cabo Blanco en torno a 1600, según el registro de gastos extraordinarios a cargo de los oficiales reales de Paita (Glave, 1993: 502).

Retornando a las palabras del padre Salinas, sobre todo cabe preguntarse, ¿qué artillería produjo concretamente Tejeda para las autoridades virreinales? Aunque, por medio de las distintas memorias, se cuenta con cifras de producción, nombres, pesos e incluso tipologías, muy pocas de estas piezas han llegado hasta nosotros ${ }^{18}$. Al margen de las dos que son objeto de este estudio,

${ }^{17}$ Como fundidor de campanas, tenemos noticia de varias de sus producciones, en concreto de 1590 data la conocida como 'Nombre de Jesús' para la iglesia de San Pedro de Lima (Vargas, 1947: 104); siete años después, las de la iglesia del Señor de la Ascensión de la ciudad de Mito (Lohmann, 1949: 218-219); o en 1619, la 'Santa María de la Concepción' para la catedral de Lima, que Francisco Meléndez, empleando para ello los mismos moldes, volvería a fundir un siglo más tarde después de haberse quebrado (Harth-Terré, 1943).

18 Memoria de la artillería hecha en el Perú desde el virrey Francisco de Toledo al virrey Marqués de Cañete. AGI, Lima, 272, fols. 451-453v. 18.V.1592; Relación de la artillería que ay en el Reyno del Piru. AGI, Lima, 128. En ambos inventarios se incluye la pieza nombrada Santa Bárbara y su peso: 58 quintales y 1 arroba. No ocurre así con la que conocemos como Santa Rufina, cuya fabricación es posterior. 
datadas en 1586 y en 1601, también existe constancia de otra fundida en Lima y que se encuentra actualmente frente al Ministerio de Defensa de Tailandia en Bangkok. Seymour Sewell nos describe «a pair of European guns each bearing two coats of arms. The first of these is barry of six horizontally, with supporters, an angel's wings. Above it is a coronet with five leaves, and this again is surmounted by an eight pointed star» (Sewell, 1922: 25). Esta descripción del primer escudo de armas concuerda a todas luces con el de don Diego Fernández de Córdoba, marqués de Guadalcázar y décimo tercer virrey del Perú. Aunque Sewell no llegó a esta identificación, el origen hispánico de estas piezas quedó confirmado por el segundo emblema heráldico: «The second coat of arms is that of the Kingdom of Leon and Castille (Spain)». Se conoce a una de estas bocas de fuego como Akkhanirut ${ }^{19}$, aunque originalmente su nombre era San Mateo; mide 2,43 metros de largo y fue labrada en 1624 por el propio Bernardino de Tejeda (Sewell, 1922: 25). El lapso de tiempo transcurrido entre la fabricación de esta pieza y la Santa Bárbara, cuya hechura se remonta a 1586, evidencia un ciclo de actividad profesional muy largo, considerando el rigor y dificultades que los maestros de este sector habían de afrontar (González, 2013: 277).

La relevancia de estos artífices ha sido tradicionalmente desatendida por la bibliografía especializada, lo que es especialmente perceptible en el caso de la fundición de Lima frente a otros establecimientos similares de Ultramar como el de Manila, La Habana o Acapulco (Aguilar, 2015: 90-91). Bernardino de Tejeda devendría en una figura esencial a la hora de esclarecer las claves técnico-militares de una plaza, el Callao, donde también se dirimiría por extensión una guerra global. Precisamente en este contexto bélico los cañones de bronce desempeñarían un papel muy destacado dentro de lo que la historiografía ha venido a denominar la «revolución militar» del siglo XVI.

\section{PRODUCCIÓN Y CONTEXTO, 1579-1601}

Pese a la trascendencia del factor geográfico, que hacía que se percibiese como inmutable la seguridad de las costas del Perú, e inconcebible

\footnotetext{
19 Thai Museums Database: www.sac.or.th.
}

sopesar las injerencias externas en ellas de los enemigos de la Corona española (Flores, 2005), a partir de 1578 se sucedieron una serie de incursiones corsarias que alteraron en cierta medida el statu quo de la región ${ }^{20}$. Con un inicial predominio inglés y posteriormente neerlandés, desde Francis Drake, Thomas Cavendish, Richard Hawkins y, con el cambio de siglo, Olivier van Noort, Joris Spielbergen o Jacques L'Hermite, todos ellos procurarían infiltrar sus naves en el Pacífico a través del estrecho de Magallanes o del cabo de Hornos, como prolongación del escenario de operaciones bélicas europeo. A la exigencia perentoria de los correspondientes aprestos militares que suponía movilizar fundidores, remesas de metales, capitales y, en definitiva, recursos científico-técnicos por todo el orbe hispano (Gallegos, 2016: 55), no siempre se respondía con la suficiente celeridad y diligencia. La documentación consultada arroja en síntesis una crisis muy acentuada y una constante falta de armamento cuyo origen podía estar motivado por la dificultad del acceso a los metales cualitativamente necesarios para las fundiciones y el elevado precio de estos. Pero también sin duda a causa de la escasez de artífices lo suficientemente hábiles para arrostrar la demanda técnicomilitar que la defensa marítima de los territorios de ultramar y el control de las rutas de navegación requerían, así como los retos logísticos asociados a estas.

La primera de estas incursiones fue la dirigida por Francis Drake. Su llegada sorprendió a don Francisco de Toledo «el viernes treze deste [febrero] a las dos de la noche» y su posibilidad de respuesta fue muy limitada porque entre otros motivos, tal y como explica en una misiva a Felipe II datada el 21 de marzo de 1579, apenas pudo armar

allí dos nauios guarnecidos con ciento y cinquenta soldados y la hartilleria que me hauia quedado que era poca y ruyn por hauerseme quedado los de chile con la que les embie en el primer socorro quando uine a este rreyno y los de panama con la que se lleuo en el harmada que fue a tierra firme (Levillier, 1924: T. VI, 102).

${ }^{20}$ Existe mucha bibliografía sobre este tema. Entre los autores que han hecho relevantes aproximaciones se cuentan Lawrence Clayton (v. gr. 1979), Pablo Emilio Pérez-Mallaína y Bibiano Torres (1987), Peter Bradley (v. gr. 2009), Guillermo Lohmann Villena (1964), Jorge Ortiz Sotelo (v. gr. 20102011), etc. 
En este sentido, el virrey Toledo vierte en su correspondencia durante aquellos meses entre 1578 y 1579 algunas ideas que es menester traer aquí a colación sobre la situación en que quedaba el Virreinato tras esta incursión y las diligencias que debían necesariamente emprenderse a fin de repeler futuros ataques. Por un lado, ponía de relieve «el desapercibimiento que [los corsarios] en el hallaron ansi de nauios con guarnición ninguna, en la mar como de artilleria ni defensa ninguna en los puertos y tenerlo descubierto todo hasta Panama» (Levillier, 1924: T. VI, 162-163). Esto podría haberlo achacado en parte al pasado reciente de insurrecciones contra la Corona, como en otra de sus cartas al expresar que «respecto de el estado en que esta esta tierra ansi como hasta agora era necesario vedar y limitar las armas assi agora parece lo contrario» (Levillier, 1924, T. VI, 125); por otro lado estaba la impostergable necesidad de promover la producción local de artillería para lo cual resultaban imprescindibles los fundidores especializados. «El fundamento y preparacion principal para la defensa y seguro de esta tierra es el artilleria y toda la que se haze y puede hazer aca es de muy poca ynportancia y excesiva costa [...] si uinieren algún par de maestros de hazer artilleria seria muy necesario» (Levillier, 1924: T. VI, 218). De acuerdo con lo expresado, abundaba en otra misiva: «aun que aca ay metales para fundir faltan los maestros que si sacan una pieça rraçinable yerran seis, y es de excesiva costa, y ansi el mandar vuestra magestad embiar maestros es lo que ymporta en quanto al artilleria» (Levillier, 1924: T. VI, 244). El virrey era consciente de que, aunque se había labrado con éxito artillería en Cuzco, las producciones limeñas habían resultado errátiles cuando no fallidas, pese a lo cual llegaron a fundirse en este periodo nueve piezas ${ }^{21}$.

En una de las cartas del licenciado Alonso de Carvajal, fechada el 9 de abril de 1580, sobre la entrada de corsarios ingleses y las prevenciones hechas para la defensa, vuelve a poner de relieve uno de los factores de riesgo que planteaba la protección militar del virreinato. «El artillería se haze aca con mucho trabajo y costo por falta de oficiales, y asi como en la otra escrevi convendrá que vuestra magestad le mande enviar dese rreyno y

${ }^{21}$ Memoria de la artillería hecha en el Perú desde el virrey Francisco de Toledo al virrey Marqués de Cañete. AGI, Lima, 272, fols. 451-453v. 18.V.1592. si se nauega por el estrecho se podrá traer aunque sea gruesa» (Levillier, 1924: T. VII, 453).

Una de las opciones barajadas, que no habían contemplado ni Toledo ni Carvajal y que se pone de manifiesto en la documentación de la época, siendo ya virrey don Martín Enríquez, suponía la remisión de armamento y de las materias primas necesarias para su fundición desde Manila al virreinato del Perú. El 12 de junio de 1581 se cursaron varias reales cédulas en este sentido pues inicialmente se consideró que en Filipinas se daban excelentes condiciones para poner en marcha la producción de cañones. El Consejo de Indias ordenaba así al gobernador, don Gonzalo Ronquillo de Peñalosa, el envío de este armamento y se daba aviso de esto tanto al virrey Martín Enríquez como a Alonso de Sotomayor, capitán general de la Provincia de Chile, puesto que la artillería recibida había de ser repartida entre ambos territo$\operatorname{rios}^{22}$.

Como resultado de todas estas diligencias arribó al Callao la nao Nuestra Señora de la Cinta, procedente de Filipinas y que transportaba, entre otras mercancías, «una pieça de bronze de 85 quintales» $\mathrm{y}$ «un pedrero de 35 quintales [...] por quenta de su Magestad». ${ }^{23}$ Pobre balance si se tienen en consideración las necesidades existentes en ambos territorios ${ }^{24}$.

Las cartas de don Martín Enríquez de Almansa evidencian una vez más «la gran falta que hay en esta tierra de armas» (Levillier, 1925: T. IX, 258). El 25 de septiembre de 1581 expresaba el virrey la necesidad de

${ }^{22}$ AGI, Filipinas, 339, L.1, F.206V-207R; AGI, Filipinas, 339, L. 1, F207R-207V; AGI, Filipinas, 339, L.1, F.207V$208 B$.

23 AGI, Patronato, 24, R.55.

24 Pese a la insistencia en el recurso de Filipinas, la situación en esta región debía de ser similar en lo referente a la producción de artillería, lo que puede desprenderse de lo escrito en 1585 por Santiago de Vera, gobernador del archipiélago: «De México se truxo a estas yslas un fundidor de artillería con mill pessos de salario el qual está ya biejo y falto de uista y de poco prouecho y a errado algunas piezas de importancia y las que haze no son buenas, es necesario vuestra magestad sea seruido de mandar ynbiar dos personas de este officio para que sigan la fundición» (AGI, Filipinas, 18A,R.3,N.16). La posibilidad de disponer de metales tampoco estaba clara si nos atenemos a lo que unas líneas más abajo expuso: «Al tiempo que se ganaron estas yslas allaron los españoles en ellas artillería que hasta agora no se a entendido de adonde se traya el metal [...] e procurado entender si aca ay mina de adonde se saque y los indios o por escusar el trauajo que se les podrá ofrecer o por no nos dar más armas jamás lo an manifestado hasta agora». 
que este Reyno se prouea de artillería porque no ay ninguna y estando abierto el estrecho no es justo que se aya de salir a pelear con las espadas en las manos $[. .$.$] tampoco ay quien sepa fvndir una pieza$ de artillería ni lo entienda sino es algun campanero y el metal de bronce es muy bronco aunque no faltan minas.

Por todo ello solicitaba encarecidamente «que vengan dos maestros que entiendan del fundir el artillería y que traygan cantidad de cobre y estaño que si no fuere por el pasalle a panamá aun seria mas barato quel que se saca en esta tierra» (Levillier, 1925: T. IX, 54). Casi dos años más tarde, en concreto el 12 de febrero de 1583, don Martín Enríquez escribía:

los oficiales de seuilla con otras cosas se deuieron de descuidar de ynbiarlos porque hasta ahora no benido ninguno y la audiencia de panama a quien yo escriui sobre ello me a escripto que no vino en la flota ningun maestro de fundir artilleria ni peloteria ni hierro para ello (Levillier, 1925: T. IX, 239).

Un mes después la vida del virrey se extinguiría, con lo que, a tenor de lo expuesto en sus despachos, es probable que la llegada de Bernardino de Tejeda se produjera en dicho intervalo. Este hecho explicaría que nuestro fundidor solo aportase a este periodo tres piezas ligeras, de en torno a los siete quintales, que llevarían los nombres de los apóstoles san Pedro, san Andrés y santo Tomé ${ }^{25}$.

En abril de 1584, la Audiencia de la Ciudad de los Reyes informó ${ }^{26}$ sobre la situación defensiva del puerto y de los navíos, así como de las piezas disponibles y de la producción de artillería que «agora se haze tan buena como en alemania». Las limitaciones cuantitativas se atribuían, no obstante, a la insuficiencia de metales, cobre y estaño ${ }^{27}$.

En carta a Felipe II de 25 de mayo de 1586 sobre materias de guerra, don Fernando de Torres y Portugal, refirió a su llegada la existencia de 26

${ }^{25}$ AGI, Lima, 128. Memoria de la artillería que ay en este Reyno hasta oy 25 de mayo de 1589.

${ }^{26}$ AGI, Patronato, 266, R. 2. Defensa de las costas Mar del Sur contra el corsario Drake.

${ }^{27}$ Pese a la necesidad de armamento, no todas las piezas disponibles pudieron ser reaprovechadas con fines bélicos. Tras una acción exitosa ante corsarios ingleses el 2 de julio, día de la Visitación de Santa Isabel, la artillería de hierro capturada de dos de sus naves fue enviada a Lima. Este conjunto de piezas, que debían de estar inutilizadas, «se puso como por padrón y memoria en algunas esquinas, y otras partes de esta ciudad y puerto del Callao que hasta hoy duraron ellas» (Jiménez, 2017: 651). piezas de artillería en el Callao y dispuso que se fundiesen otras 14 «con los metales que se pudieron hauer que con gran dificultad los huuo para ellas en especial estaño que fue menester tomar platos y escudillas de las personas que las tenían y fundillas» (Levillier, 1925: T. X, 122-123). Todo ello con el objetivo de proporcionar capacidad de fuego a los navíos que transportaban las remesas de metales preciosos y a una todavía embrionaria Armada del Mar del Sur que había de ser el garante de la seguridad en la Carrera entre Tierra Firme y el Perú (Pérez-Mallaína/Torres, 1986). El virrey se lamentaba en la misma correspondencia de que hecho este esfuerzo «por acudir a lo mas necesario para nos que es la seguridad de la plata de Vuestra Magestad nos quedamos en este puerto sin ninguna pieza de artillería y ymporta y conuiene lo que se dexa considerar que aya muchas entrambas partes y en algunas otras deste Reyno». También a través de esta carta aduce que una de las principales dificultades es

la falta de metales que aunque ay algún cobre que se trae de chile y saca en esta tierra no es de prouecho sino que se refina mucho y es muy costoso y aunque entendido que ay algún estaño lo seria mas el sacarlo por lo qual conuiene que Vuestra Magestad se sirua de mandar ymbiar en los primeros nauios que uengan mucha cantidad de entrambos metales en planchas con que para todo lo referido se pueda hazer suficiente artillería y algún buen artillero porque aunque aquí ay uno que no lo hace mal podría ser mejor (Levillier, 1925: T. X, 122-123).

La primera cuestión hizo que el empleo de metal ligado, resultante de campanas quebradas o piezas de artillería deficientes, fuera algo usual debido al elevado valor de la aleación de bronce ${ }^{28}$. Se conoce la reutilización en 1584 de ocho piezas provenientes de Nueva España que «por su defectuosa fabricación y endeblez hubo que rehacer» (Lohmann, 1964: 26). Otro ejemplo de esto se dio el 20 de junio de 1586, cuando el factor y veedor de la Real Hacienda en Lima, don Francisco Manrique de Lara hizo entrega a Bernardino de Tejeda de una campana ya inservible de la catedral cuyo peso era de 27 quintales, 1 arroba y 8 libras «para la fundición de media culebrina que haze para el fuerte del puerto del Callao» (Vargas, 1955: 25).

28 «El mejor metal que hasta agora se ha hecho para pieças de artillería es el buen cobre con el buen estaño» Juan de Escalante. Itinerario de navegación de los mares y tierras occidentales. 
Respecto a la segunda cuestión, no parece muy aventurado suponer que el artillero al que hace alusión el conde de Villardompardo es el propio Tejeda. Según lo referido, los trabajos del sevillano no parecían contar con su total aprobación, por lo que disponer de otros fundidores sería uno de sus principales requerimientos. Cabría argumentar aquí sin embargo, que se trata de documentos en cuya propia pragmática textual habían de servir para reclamar más recursos destinados al esfuerzo bélico, y uno de cuyos propósitos principales era precisamente ese. Lo que, por otro lado, obedecía también al apremio con el que se debía responder a una situación militar dada.

En una nueva carta a Felipe II, datada el 23 de noviembre de 1586, don Fernando de Torres y Portugal vuelve a insistir en la insuficiencia armamentística, motivada por las limitaciones del suministro de metales «y que es muy necesario un buen artillero para que lo haga porque aunque aquí ay uno que no lo haze mal podría ser mejor y es solo y si faltase no se podría hazer cosa alguna» (Levillier, 1925: T. X, 204). Unos meses más tarde, en febrero de 1587 , reitera que la producción de artillería dependía de la calidad de los meta$\operatorname{les}^{29}$, pues aunque

me an traydo algun estaño y paresce razonable y creo se traera algun cobre y de chile se a traydo todo será menester en especial para reboluer los metales de alla con los de aca porque se entiende no tienen la perfeccion que conuiene y asimismo se sirua de mandar embiar vn buen artillero porque como tengo escrito a Vuestra Magestad aca no ay mas de uno y no podra hazer tanta artillería como la que es menester (Levillier, 1925: T. X, 260).

Ese mismo año, en 1587, se produciría la entrada de Thomas Cavendish en el Mar del Sur y sus consiguientes ataques a los puertos de Arica, Paita y Guayaquil. La posición de Tejeda en el virreinato del Perú empezaba a ser tan preeminente que su pericia llegaría a servir como uno más de los argumentos en la investigación contra don

${ }^{29}$ El problema constatado no radicaba exclusivamente en la escasez de insumos para la artillería, sino también en el empleo que se le daba a las piezas. Así en la Instrucción que el virrey don García Hurtado de Mendoza, marqués de Cañete, dio al almirante Hernando Lamero el 20 de febrero de 1591 se señalaba entre otras cuestiones que si alguna pieza reventaba había de investigarse a fondo «por lo mucho que a su magestad le cuesta cada pieça de artilleria» y a fin de dilucidar «si rebento por culpa y malicia del artillero o por hauerla cargado demasiado» (Levillier, 1926: Tomo XII, 1ª. Parte, 219-220).
Fernando de Torres y Portugal al concluir su mandato. Así pues, el licenciado Alonso Fernández de Bonilla, inquisidor apostólico de la Nueva España, entre los cargos articulados en marzo de 1593, atribuía al conde de Villardompardo

que estando en esta ciudad Bernardino de Tejada, maestro de fundir artillería experimentado, encomendó el hacer una pieza grande de crujía para una galera a Jusepe Bono, extranjero, no conocido por solo favor y amistad que le hacía Don Gerónimo de Torres y Portugal, su hijo, por haberle traído consigo de Panamá, y le mandó entregar todos los materiales y pertrechos que él le pidiese (Hanke, 1975: 68).

Este encargo, después de un dispendio de «3346 pesos y dos reales», así como el cobre y estaño que fue necesario, resultó según la acusación un fracaso «porque dicha pieza, después de fundida, salió inútil y falsa y como tal se mandó deshacer en la real audiencia» ${ }^{30}$. Aun así el balance en lo que respecta a la dotación de artillería que realiza el conde de Villardompardo en su memoria gubernativa es el siguiente: «54 piezas [...] que pesaron 1132 quintales. / Dos cañones de crujía y un falconete. / Otro cañón de crujía. / Seis piezas compradas que pesaron 16 quintales, 1 arroba y 16 libras» (Hanke, 1978: T. I, 241).

Pese a las manifiestas reticencias con respecto al cobre proveniente de Chile, el tiempo demostraría que eran en parte infundadas. El mejor testimonio de este cambio de actitud es un escrito que se encuentra entre la documentación novohispana del virrey don Luis de Velasco donde se informa de la artillería que don García Hurtado de Mendoza ordenó fundir en Lima, con vistas al traslado de algunas piezas a Filipinas, en concreto para la defensa de Ternate.

Que él labró en Lima ciento y quarenta pieças de treynta hasta sesenta quintales y dos culebrinas de noventa y que toda le salió en estremo buena — que las primeras fundiciones hizo de pieças quebradas y de algún metal que recoxió y estas le salieron muy cortas - hasta que le traxeron metal de Chile de las minas de Coquinbo puesto en Lima a catorze o quinze ducados [...] y que la artillería que labró

\footnotetext{
${ }^{30}$ Sobre Giuseppe Bono, hidalgo siciliano originario de Palermo, y su llegada a Indias con un ingenio para pescar perlas pueden consultarse en el Archivo de Indias los siguientes documentos: AGI/ Indiferente, 2094, N. ${ }^{\circ}$ 153; AGI/ Indiferente 426, L. 27, F. 97V; AGI/ Indiferente 1952, L. 2, F. 283; 1952, L. 2, F. 282V-283; AGI/ Indiferente, 426, L. 27, F. 95V.
} 
deste metal de Coquinbo es la mexor que xamas se a bisto ${ }^{31}$.

Sobre el maestro que hizo posible esto se nos dice que «le dio alguna renta y otras mercedes» y «que se llama Texeda y que es en estremo bueno y tiene en pie la fundición de Lima de almireces y campanas y otras cosas y negros oficiales».

El documento tiene un gran valor y pone de relieve varias cuestiones: en primer lugar, la razonable calidad del cobre chileno, lo que constataría Luis de Rosales años más tarde al afirmar que de este mineral se transportaba

al Perú considerable cantidad todos los años, assi para la fundicion de la artilleria, que la tiene excelente aquel Reyno, como para las oficinas de los caldereros. Y el Rey ordenó por cedula de 20 de octubre de 1624 al Marqués de Guadalcazar, Virrey del Perú que hiziesse asiento en la ciudad de Coquimbo, que también se llama la Serena y le remitiesse la mayor cantidad de cobre que pudiesse, porque dize es excelente y de bonissima ley para la artillería (Rosales, 1877: 212)

En segundo lugar, la distribución de las piezas limeñas a otras regiones, en concreto se nos dice que se enviaron «quatro /o seis pieças» al puerto de Arica (Chile), otras cuatro a Guayaquil y seis a Panamá; en tercer lugar, el prestigio adquirido por el maestro sevillano; y por último, resulta significativa la referencia a los «negros oficiales $\rangle^{32}$, que aporta una visión clara del elemento humano en el específico ámbito laboral de estas maestranzas de artillería.

La derrota de Richard Hawkins a mediados de 1594 (León, 1979: 251-254) no hizo que las nuevas autoridades virreinales bajaran la guardia, más bien al contrario, y en ese sentido se manifestaba don Luis de Velasco dos años después de tomar posesión del cargo.

Para si por el estrecho de Magallanes reventase algún corsario, se han hecho por la costa desde aquí a chile las preuenciones conuenientes y en el puerto del callao tengo aderezadas cuatro naos de armada que Vuestra Magestad tiene [...] Ansimismo he mandado hazer poluora, porque halle mucha falta

\footnotetext{
${ }^{31}$ Nota sobre lo que dice el virrey del Perú Marqués de Cañete acerca de lo que se le preguntó de la artillería que labró en el Perú y lo que de ella se podía enviar a Filipinas. AGI, México, 27, N.35, 43R-46V.

${ }^{32}$ Pese a su estatus de sirvientes solían ser trabajadores altamente cualificados.
}

della, y fundir pieças de artilleria que eran nescesarias para acauar de armar las naos [...] y todo lo demas que parece ser necesario para la defensa de la tierra y ofensa de los enemigos se va previniendo (Levillier, 1926: T. XIV, 26-27).

Tal planificación no sería estéril pues a finales de febrero de 1600 se produciría la entrada en el Pacífico de la flota de Olivier van Noort. Los corsarios, exponía don Luis de Velasco el 5 de mayo de 1600 ,

traen gruesas naos fuertes muy artilladas y con muchas municiones por la abundancia que de todo esto tienen en sus tierras las nuestras por el contrario son mas pequeñas y con menos artilleria balas y poluora porque todo cuesta aquí gran suma de plata como se vee por las pieças que he mandado fundir que sale cada quintal a cincuenta y dos pesos (Levillier, 1926: 263).

Entre estas últimas producciones se encontraban dos medias culebrinas vaciadas por Tejeda que habían de incorporarse a la dotación de un navío «de los merchantes» destinado a quedar de armada en el puerto a principios de 1600 ante la ausencia de la flota al mando del general Juan de Velasco (Medina, 1923: 250). El acuerdo de la Real Audiencia de Lima del 22 de enero de 1600 sobre estas dos medias culebrinas nos proporciona una idea concreta de las garantías que ofrecía del maestro sevillano a la hora de responder por sus trabajos

porque la una de ellas tiene en la boca dos escarabajillos y la otra uno en la misma parte, que dicen no son de consideración, como está declarado por los oficiales que hicieron la prueba, con todo eso parece que Bernardino de Texeda se obligue, como lo ha ofrecido, que si por estas partes faltaren las piezas o algunas de ellas en algún tiempo las tornará a hacer y fundir a su costa (Medina, 1923: 252).

También resulta reveladora la propuesta del virrey a la Real Audiencia de Lima de replantear la tipología de las piezas producidas y diversificar en adelante la potencia de fuego embarcada (Medina, 1923: 251).

Aunque la artillería que las cuatro naos de armada que S. M. tiene en este puerto es en número y bondad la que pareció podría bastar para ellas, la experiencia ha mostrado que por ser casi todas largas y de poca munición son de menos efecto y más impedimento que convendría en las ocasiones de pelear, y así parece serán muy a propósito y ne- 
cesarias ayudarlas en diez y doce medios cañones de a cincuenta quintales y veinte y tres o veinte y cuatro libras de bala, que serán más fáciles de limpiar y cargar y se tirarán más veces y harán mayores y mejores efectos en las naos contrarias [...] y en caso que se hayan de fundir si será por cuenta de S. M., dando los materiales necesarios a Bernardino de Texeda y pagándole su trabajo, o encargándole toda la fábrica y que él los busque, compre y ponga y se le paguen por la hechura, como otras veces se ha hecho.

A este respecto finalmente la Real Audiencia aprobó la fundición de ocho medios cañones y resolvió «que el asiento se tome por los oficiales reales en la forma en que se ha hecho otras veces [...] porque el dar material y pagar la manifatura será de más costa a la Real Hacienda de S.M.» (Medina, 1923: 252).

En su mayoría estas producciones tendrían como destino la Armada del Mar del Sur y el puerto del Callao, aunque en otros casos serían demandadas por otros territorios. Cuando en 1597, don Alonso de Sotomayor fue nombrado presidente de la audiencia panameña, y gobernador y capitán general de Tierra Firme, uno de sus principales retos sería la obtención de los recursos militares necesarios para su defensa. Existe un volumen considerable de documentos a este respecto $^{33}$. Don Alonso era consciente de que residía «en el Perú un gran maestro de fundiciones y mucho metal» y proponía que se ordenase al virrey «se le embiase con los materiales y demás personas necessarias para fundir lo que fuere menester junto al río de Chagre» ${ }^{34}$. La cuestión es que ni en Panamá ni en Portobelo existían fundiciones de artillería, aunque como determinó el cronista Pedro de Valencia respecto a esta última, se «podría muy bien porque hay mucha leña y buen barro para los moldes experimentado en labor de campanas. El metal se podría traer de Chile donde es famoso, o de la isla de Cuba». Según el cronista extremeño se pertrechaban «estos castillos de artillería y munición de balas de los Reinos de España, y aunque se podrían proveer del Perú artillería, como ya se ha traido alguna con gran trabajo» (Valencia, 1993: 232).

33 AGI, Panamá, 1, N. 139. Memoria de la artillería que se necesita en las fortificaciones de Puertobelo, hecha por Alonso de Sotomayor, 15 noviembre 1597.

34 Los despachos que solicita Alonso de Sotomayor. AGI, Panamá, 1, N. 101. 25-I-1597.
Según lo analizado también Chile, dada su gran significación estratégica fue un espacio receptor de armamento proveniente de la Ciudad de los Reyes. A finales de marzo de 1599, el nuevo gobernador, don Francisco de Quiñones, solicitó cuatro piezas de artillería «para llevar a aquella tierra». En respuesta a dicha petición el virrey don Luis de Velasco determinó «que sean dos que estaban en poder de Bernardino de Texeda y otras dos que están en el puerto y Callao desta ciudad nombradas (en blanco)» (Medina, 1923: 225).

\section{CONCLUSIONES}

Tal y como hemos visto, las dos piezas de artillería estudiadas constituyen un documento excepcional en sí mismas, un testimonio lo suficientemente revelador como para poner en relación los escenarios donde se desempeñaron, el fundidor responsable de su manufactura y los tratados de la época sobre fabricación y diseño de este armamento. Ambas piezas, de idéntica tipología y distinta datación, permiten apreciar una muy perceptible evolución, donde se han atemperado algunos elementos ornamentales y donde existe una ligera reducción de la longitud y del calibre. Asimismo, de su examen cabe constatar la realidad de ese otro cargamento oculto en el ánima de ambas piezas. Según lo analizado, la aparición de elementos orgánicos y monedas en su interior plantea cuestiones muy interesantes sobre el tráfico marítimo o la vida a bordo, que habitualmente no figuran en los registros escritos.

Resulta imprescindible, no obstante, recalcar que, en algunos de sus aspectos, esta es una investigación de carácter preliminar. Y como tal está sujeta a la aparición de materiales inéditos, tanto los provenientes del registro documental como los aportados por el registro arqueológico.

Pese al gran interés que suscita todo lo relativo a la historia militar, no abundan los estudios individualizados sobre talleres de fundición de artillería en los territorios de Ultramar. Algunos de los artífices que pusieron en pie estos establecimientos, y otros, ya fueran alarifes, canteros, lapidarios, escultores, carpinteros, etc. «llegaron a ser personajes de consideración y con fortuna», «individuos con escuela de arte en España que vinieron a América - previo el expedienteo en la Casa de Contratación de Sevilla- a trabajar con sus conocimientos en las imponentes obras que erigían las autoridades civiles y las comunidades 
religiosas» (Harth-Terré, 1945: 7). Recobrar estas vidas a partir de la documentación es un reto, y no carente de complejidad. Como tampoco lo es analizar dichas fundiciones «desde la perspectiva, no solo de la historia militar, sino desde la historia económica global, incluso desde el mundo del trabajo» (Gallegos, 2017: 103).

En lo referente a la identificación de nuevas piezas de artillería, esta posibilidad provendrá, al igual que en el caso de las medias culebrinas conocidas como Santa Bárbara y Santa Rufina, de la investigación arqueológica de otros naufragios. Según Ricardo Cappa, el virrey Luis Enríquez de Guzmán, conde de Alba de Liste, entre los años 1655 y 1661

viendo que buena parte de la artillería destinada a la defensa del Callao estaba inservible la fundió toda y de ella sacó, entre otras piezas, dos celebres culebrinas de á 24, que medían, de la lámpara al brocal, siete varas cada una. No sería difícil que para esta refundición se echara mano de las que había fundido hacia 1610 Juan Bernardino de Tejeda en Lima, en los talleres que tuvo junto a San Agustín (Cappa, 1892: 176).

Dada la frecuencia con la que se reutilizaban estos metales, cobran especial relevancia los proyectos de investigación que pudieran desarrollarse sobre navíos de la Armada del Mar del Sur (Agudo, 2013), en tanto en cuanto se han constituido como «cápsulas del tiempo». Pueden citarse algunos casos como el galeón San Andrés, Capitana de la Mar del Sur, perdido el 20 de septiembre de 1600 «con más de doscientos y cincuenta hombres de mar y guerra y cincuenta piezas de bronce» (López de Caravantes, 1985: 128) durante una tormenta entre Colima y la Barra de Navidad (Pérez-Mallaína y Torres, 1987: 257; Bradley, 2009: 32) o el galeón Santa Ana, hundido frente a Cerro Azul el 17 de julio de 1615, como consecuencia del enfrentamiento con la escuadra de Spielbergen en el combate naval de Cañete (Clayton, 1979; Ortiz, 2010-2011).

\section{BIBLIOGRAFÍA}

Agudo Rey, C. (2013): «El patrimonio sumergido en las costas peruanas. La importancia del Virreinato de Perú y su defensa naval durante el siglo XVII». I Congreso de Arqueología Náutica y Subacuática Española, Cartagena 14, 15 y 16 de Marzo de
2013. Madrid, Ministerio de Educación, Cultura y Deporte: 373-385.

Aguilar Escobar, A. (2015): «Noticias sobre las fundiciones de artillería de Ultramar en los siglos XVII y XVIII». La economía maritima en España y las Indias. 16 estudios. San Fernando: 69-96.

Alaba, D. de (1590): El perfecto capitán instruido en la disciplina militar, y nueva ciencia de la artilleria. Madrid, por Pedro de Madrigal.

Alvear y Ward, S. (1891): Historia de D. Diego de Alvear y Ponce de León. Madrid, Imprenta de Luis Aguado.

Arántegui y Sanz, J. (1891): Apuntes históricos sobre la Artillería Española. Madrid, Imprenta del Cuerpo de Artillería.

Bradley, P. (2009): Spain and the Defence of Peru 1579-1700. Royal Reluctance and Colonial SelfReliance. Morrisville N.C., Lulu.

Cappa, R. (1892): Estudios críticos acerca de la dominación española en América. Parte 3. Industrias mecánicas. Madrid, Librería Católica de Gregorio del Amo.

Clayton, L. A. (1979): «Cañones en Cañete, 1615: la Armada del Mar del Sur y la defensa del Virreinato del Perú». Memoria del Tercer Congreso Venezolano de Historia. Del 26 de septiembre al $1^{\circ}$ de octubre de 1977. T. I. Caracas, Academia Nacional de la Historia: 441-462.

Collado, L. (1592): Plática Manual de Artillería. Milán, por Gotardo Poncio.

Diana, M. J. (1851): Capitanes ilustres y revista de libros Militares. Madrid, J. A. Ortigosa.

Díaz, F. (2000): «Teórica y práctica del arte de la guerra en el siglo XVII hispano. Julio César Firrufino y la artillería», Anales de la Historia del Arte, 10: 169-205.

Fernández Duro, C. (1902): Armada española desde la unión de los reinos de Castilla y de Aragón. Tomo VIII. Madrid, Imprenta de la Real Casa.

Firrufino, J. C. (1626): Plática manual y breve compendio de artillería, Madrid, por la viuda de Alonso Martin.

Firrufino, J. C. (1648): El perfecto artillero theorica $y$ practica. Madrid, Juan de Noort.

Flores Guzmán, R. (2005): «El enemigo frente a las costas. Temores y reacciones frente a la amenaza pirata, 1570-1720», C. Rosas Lauro (ed.), El miedo en el Perú. Siglos XVI al XX. Lima, Seminario Interdisciplinario de Estudios Andinos, Fondo Editorial de la Pontificia Universidad Católica del Perú: 33-50.

Fondevila Silva, P. y Sánchez Baena, J. J. (2012): «Una nueva pieza de artillería de galeras del siglo XVI: el esmeril bastardo "Matacapitanes"». Gladius, XXXII: 185-210. https://doi.org/10.3989/ gladius.2012.0009

Gallegos Ruiz, E. (2016): «La producción de artillería de bronce en Acapulco (1601-1616), un elemento 
del sistema defensivo del Pacifico». Red de Estudios Superiores Asia-Pacifico, Palabra de Clio, 3: 39-59.

Gallegos Ruiz, E. (2017): «La circulación oceánica de tecnología artillera, Sevilla-Manila siglos XVIXVIII». J. Olveda (coord.), Relaciones intercoloniales. Nueva España y Filipinas. Zapopan (Jalisco), El Colegio de México: 89-103.

García Ramírez, S. y Marcos Alonso, C. (2014): El último viaje de la fragata Mercedes. La razón frente al expolio. Un tesoro cultural recuperado. Madrid, Ministerio de Defensa, Acción Cultural Española (AC/E) y Ministerio de Educación, Cultura y Deporte.

García-Torralba Pérez, E. (2010): La artillería naval española en el siglo XVIII. Madrid, Ministerio de Defensa.

Gestoso y Pérez, José (1889): Ensayo de un diccionario de los artifices que florecieron en Sevilla: desde el siglo XIII al XVIII inclusive. Sevilla, Oficina de la Andalucía Moderna. 3 vols.

Gil Montero, M. L. A. (2001): «Extración de cloruros de piezas arqueológicas metálicas recuperadas del fondo del mar». Boletín del Instituto Andaluz de Patrimonio Histórico, 35: 87-89.

Glave, L. M. (1993): «La puerta del Perú: Paita y el extremo norte costeño, 1600-1615». Bulletin de l'Institut français d'études andines, 22 (2): $497-$ 519.

González Enciso, A. (2013): «Asentistas y fabricantes: el abastecimiento de armas y municiones al estado en los siglos XVII y XVIII». Studia Historica. Historia moderna, 35: 269-303. https://doi. org/10.14201/shhmo201335269303

Hanke, L. (1975): «El visitador Lic. Alonso Fernández de Bonilla y el Virrey del Perú, el Conde del Villar (1590-1593)», en Memoria del $2^{\circ}$ Congreso Venezolano de Historia. T. II. Caracas, Academia Nacional de la Historia: 11-128.

Hanke, L. (1978) Los virreyes españoles en América durante el gobierno de la Casa de Austria Perú. Madrid, Atlas. 7 vols.

Harth-Terré, E. (1945): Artífices en el Virreinato del Perú (Historia del arte peruano). Lima, Imprenta Torres Aguirre.

Jiménez Jiménez, I. (2017): Noticias generales del estado que han tenido las armas. Una nueva crónica del Perú (1578-1683). Sevilla, Editorial Universidad de Sevilla.

Lechuga, C. (1611): Discurso del Capitán Cristoval Lechuga, en que trata de la Artillería y de todo lo necessario á ella. Milán, por Marco Tulio Malatesta.

León Borja, D. (1979): «Guayaquil y la Real Armada del Mar del Sur, 1579-1624». Memoria del Tercer Congreso Venezolano de Historia, del 26 de septiembre al $1^{\circ}$ de octubre de 1977. T. I. Caracas, Academia Nacional de la Historia: 239-298.
Leste Contreras, T. de (2013): «La fragata de guerra Mercedes: ¿El último caso?», Revista General de Marina, 265: 17-40.

Levillier, R. (dir.) (1921-1926): Gobernantes del Perú: cartas y papeles. Siglo XVI. Documentos del Archivo de Indias. Madrid, Rivadeneyra. 8 vols.

Lohmann Villena, G. (1949): Las minas de Huancavelica en los siglos XVI y XVII. Sevilla, Escuela de Estudios Hispano-Americanos.

Lohmann Villena, G. (1964): Las defensas militares de Lima y Callao. Sevilla, Escuela de Estudios Hispano-Americanos.

López de Caravantes, F. (1985-1989): Noticia general del Perú. Madrid, Atlas. 6 vols.

Medina, J. T. (ed.) (1923): Los holandeses en Chile. Santiago de Chile, Imprenta Universitaria. (Colección de historiadores de Chile y de documentos relativos a la historia nacional, t. XLV).

Negueruela Martínez, I., Castillo Belinchón, R. y Sierra Méndez, J. L. (2015): El pecio de Nuestra Señora de las Mercedes. Campaña de prospección y excavación de agosto 2015. Madrid, Ministerio de Educación, Cultura y Deporte.

O'Donnell y Duque de Estrada, H. (2013): El litigio por el pecio de la fragata "Mercedes". Razones históricas de España. Madrid, Real Academia de la Historia.

Ortiz Sotelo, J. (2010-2011): «Nuevos detalles sobre la expedición de Spielbergen en la Mar del Sur». Derroteros de la Mar del Sur, 18-19: 97-119.

Ortiz Sotelo, J. (2012-2013): «Cañones peruanos en la Academia Naval de los Estados Unidos». Derroteros de la Mar del Sur, 20-21: 63-72.

Pérez Canepa, R. (1946): «La capilla de Tejeda, en la iglesia de San Agustín de Lima». Revista del Instituto Peruano de Investigaciones Genealógicas, 1: 17-33.

Pérez-Mallaina, P. E., y Torres Ramírez, B. (1987): La Armada del Mar del Sur. Sevilla, Escuela de Estudios Hispano-Americanos, CSIC.

Plaza, L. de la; Martínez, J. M. y Vaquero, J. I. (2016): Guía para identificar los personajes de la mitología clásica. Madrid, Cuadernos Arte Cátedra.

Ríos, V. de los (1767): Discurso sobre ilustres autores e inventores de artillería que han florecido en España, desde los Reyes Católicos hasta el presente. Madrid, por Joachin Ibarra.

Riva Agüero, J. de la (1914): «Descripción anónima del Perú y de Lima á principios del siglo XVII compuesta por un judío portugués y dirigida a los Estados de Holanda». Congreso de Historia y Geografia Hispano-Americanas celebrado en Sevilla en abril de 1914. Actas y memorias. Madrid, Establecimiento Tipográfico de Jaime Ratés: 347-384.

Rosales, Diego de (1877): Historia general de el Reyno de Chile, Flandes indiano. Valparaíso, Imprenta del Mercurio. 
Rovira, F. X. (1773): Tratado de artillería para el uso de los cavalleros guardias-marinas en su Academia. Cádiz, en la imprenta de la misma Academia. Serrano Mangas, F. (1989): Armadas y flotas de la plata (1620 - 1648). Madrid, Banco de España.

Sewell, S. (1922): «Notes on some old Siamese guns». Journal of the Siam Society, 15 (1): 1-43.

Soler, J. M. (2009): Nobleza española: grandeza inmemorial 1520. Madrid, Visión Net.

Valencia, P. de (1993): Relaciones de Indias. 1, Nueva Granada y virreinato de Perú. Edición de Francisco Javier y Jesús Fuente Fernández. León, Se- cretariado de Publicaciones de la Universidad de León.

Vargas Ugarte, R. (1947): Ensayo de un diccionario de artifices de la América meridional. Lima, Talleres Gráficos A. Baiocco.

Vargas Ugarte, R. (1955): Ensayo de un diccionario de artífices de la América meridional. Apéndice. Lima: Talleres Gráficos A. Baiocco.

Vega, E. de la (1992): Sevilla y la Real Fundición de Cañones. Sevilla, Guadalquivir Ediciones.

Vigón, J. (1947): Historia de la Artillería española. Tomo I. Madrid, CSIC, Instituto Jerónimo Zurita. 